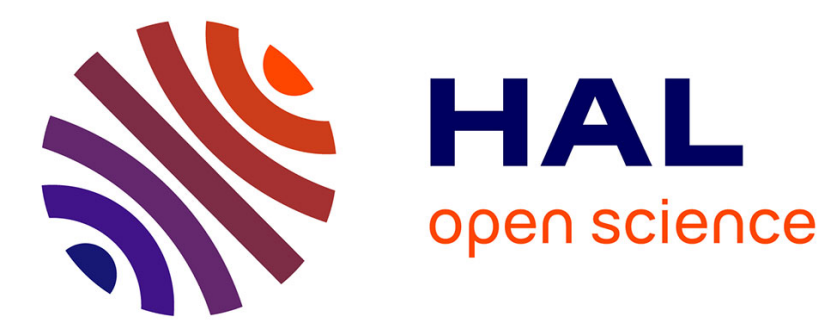

\title{
Une place pour l'artisanat mycénien ?
}

Laetitia Phialon

\section{To cite this version:}

Laetitia Phialon. Une place pour l'artisanat mycénien ?. Bulletin de Correspondance Hellenique, 2016, 139-140.1, pp.1-42. 10.4000/bch.335 . hal-02614952

\section{HAL Id: hal-02614952 \\ https://hal.science/hal-02614952}

Submitted on 3 Jun 2020

HAL is a multi-disciplinary open access archive for the deposit and dissemination of scientific research documents, whether they are published or not. The documents may come from teaching and research institutions in France or abroad, or from public or private research centers.
L'archive ouverte pluridisciplinaire HAL, est destinée au dépôt et à la diffusion de documents scientifiques de niveau recherche, publiés ou non, émanant des établissements d'enseignement et de recherche français ou étrangers, des laboratoires publics ou privés. 


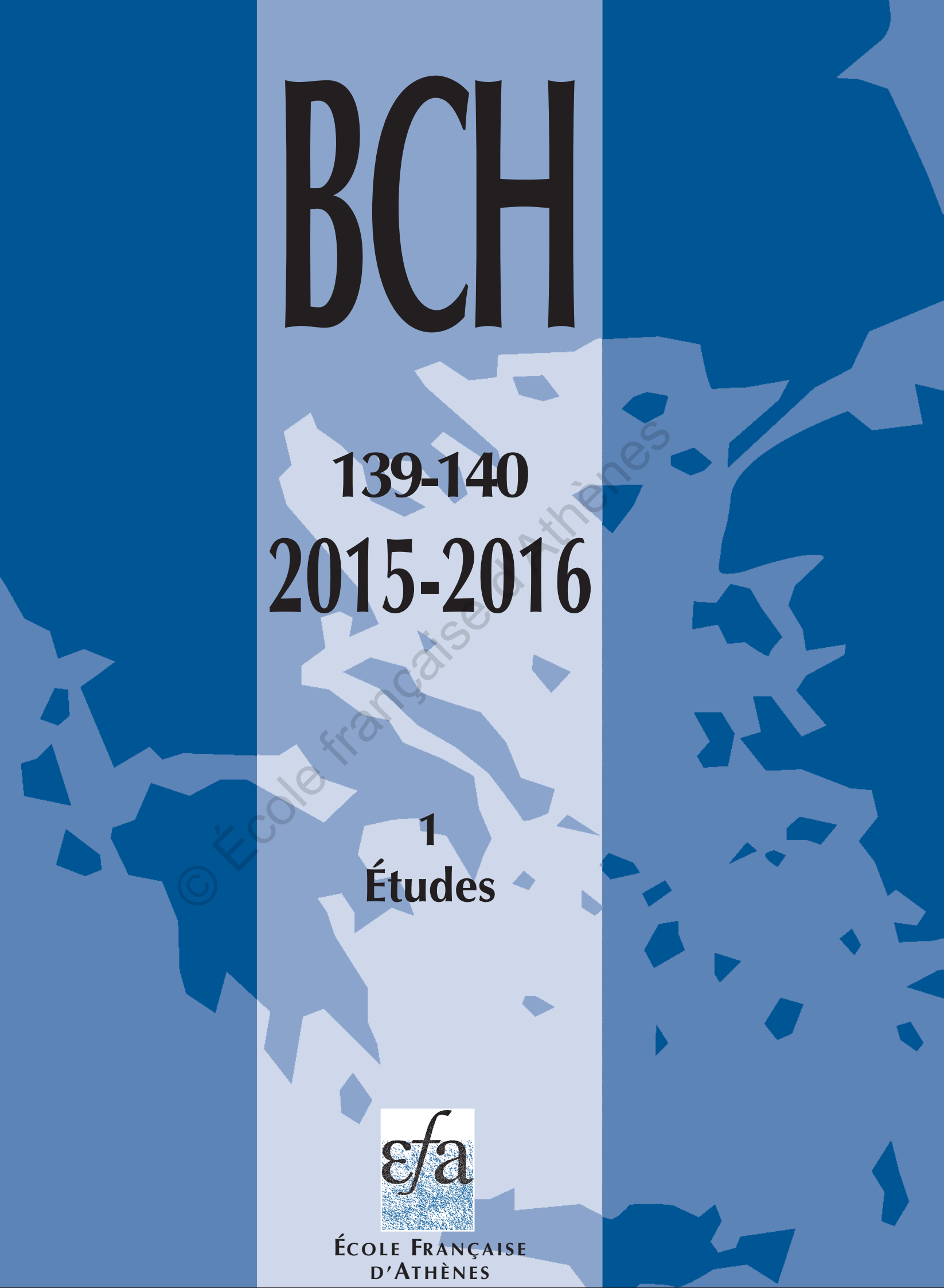

B ULLET IN DE CORRESPON D NCE HELLÉN IQUE 


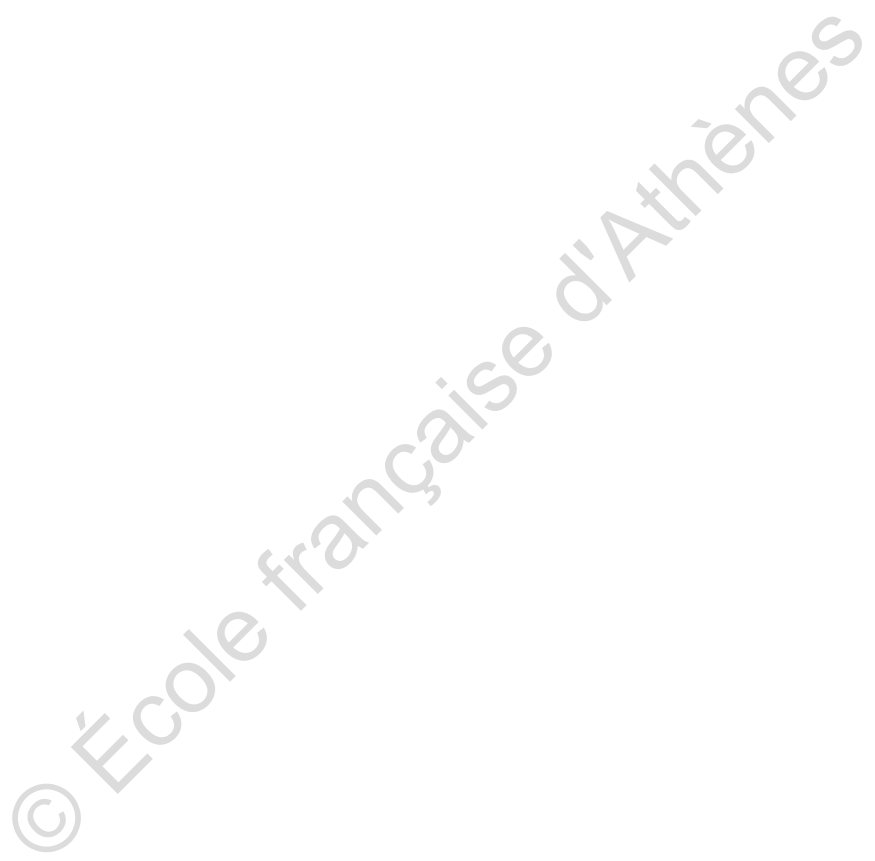




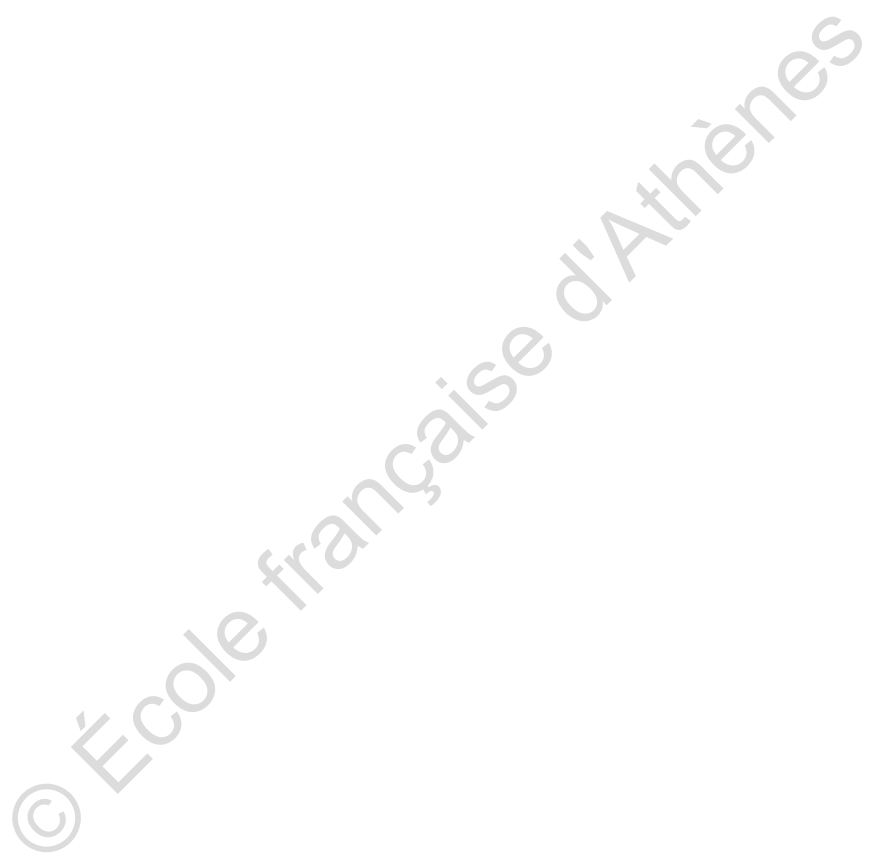


É C O L E F R A N ÇA I S E D'A T H È N E S

\author{
B U L L E T I N \\ DE CORRESPONDANCE \\ HELLÉNI QUE
}

$\mathrm{BCH}$

$139-140$

2015-2016 


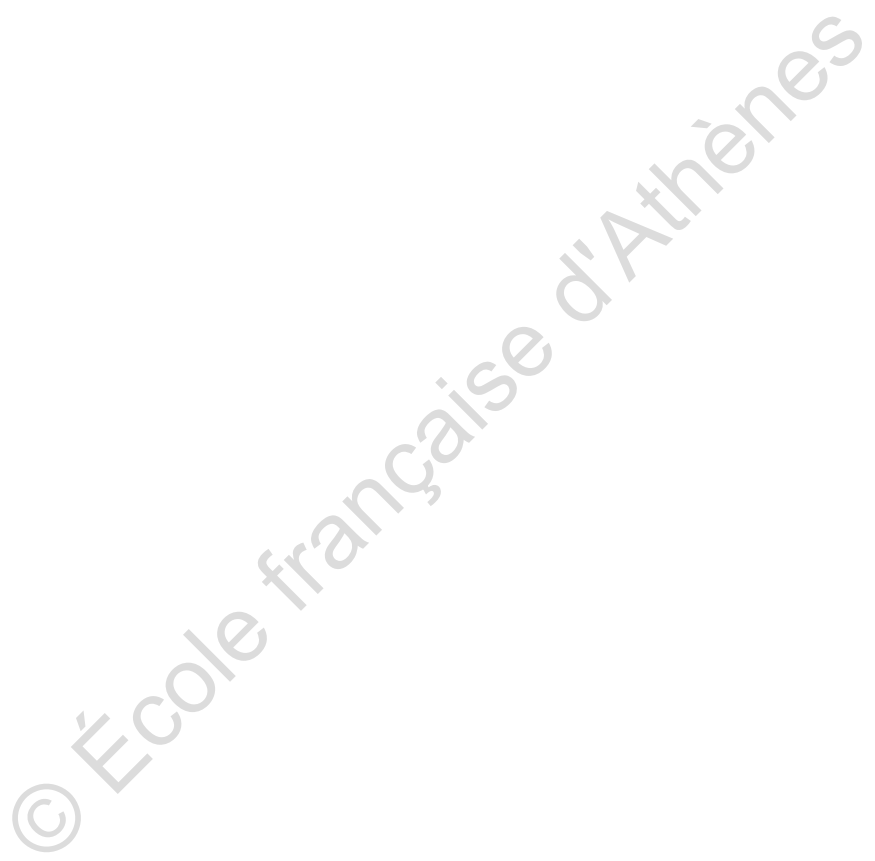


É C O L E F R A N ÇA I S E D'A T H È NE S

\author{
B U L L E T I N \\ DE CORRESPONDANCE \\ HELLÉNIQUE
}

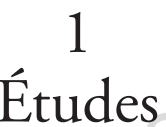

$\mathrm{BCH}$

$139-140$

2015-2016 


\title{
É C O L E F R A N Ç A I S E D'A T H È N E S
}

\author{
B U L L E T I N \\ DE CORRESPONDANCE \\ HELLÉNIQUE \\ $139-140.12015-2016$
}

Comité de rédaction : Alexandre Farnoux, directeur Géraldine HuE, responsable des publications

\section{COMITÉ DE LECTURE}

Le comité de lecture de l'École française d'Athènes est composé de trois membres de droit et de neuf membres désignés par le conseil scientifique sur proposition du directeur. Sa composition actuelle est la suivante (conseil scientifique de l'École française d'Athènes du 25 juin 2012) :
Membres
- le directeur de l'École française d'Athènes : Alexandre Farnoux
de droit
- le directeur des études antiques et byzantines : Julien Fournier
- le directeur des études modernes et contemporaines : Anastassios ANASTASsiadis
Membres $\quad$ Sont membres désignés des personnalités scientifiques françaises ou étrangères (mais francophones), reconnues et désignés de dimension internationale. Le choix en est fait de manière à assurer la meilleure représentation possible des champs disciplinaires concernés. Leur mandat coïncide avec la durée d'un contrat quinquennal.
- Polixeni Adam-Veleni, Directrice du musée archéologique de Thessalonique
- Olivier Deslondes, Professeur des Universités, Université Lyon 2-Lumière
- Emanuele Greco, Directeur de l'École italienne d'Athènes
- Jean Guilaine, Professeur au Collège de France
- Miltiade B. Hatzopoulos, Directeur de recherche, Directeur du Centre de recherche sur l'Antiquité gréco-romaine (Fondation nationale de la recherche [EIE] - Athènes)
- Catherine Morgan, Directrice de l'École britannique d'Athènes
- Kosmas Pavlopoulos, Professeur à l'Université Harokopio d'Athènes
- Jean-Pierre Sodini, Professeur émérite de l'université Paris 1 - Panthéon-Sorbonne
- Georges Tolias, Directeur de recherche en histoire contemporaine, Institut de recherche néo- hellénique (Fondation nationale de la recherche [EIE] - Athènes)

Le comité de lecture fait appel en tant que de besoin à des experts extérieurs.

Révision des textes : EFA, Sophie Duthion

Traduction et révision des résumés en grec : Pavlos Karvonis

Traduction et révision des résumés en anglais : Katie Low

Réalisation en PAO : EFA, Guillaume Fuchs

Impression et reliure : n.v. PEETERS s.a.

(C) École française d'Athènes, 2016

6, rue Didotou GR - 10680 Athènes www.efa.gr

Dépositaire : de Boccard Édition-Diffusion 11, rue de Médicis F - 75006 Paris www. deboccard.com

ISBN 978-2-86958-286-6

ISSN 0007-4217

Reproduction et traduction, même partielles, interdites sans l'autorisation de l'éditeur pour tous pays, y compris les États-Unis. 


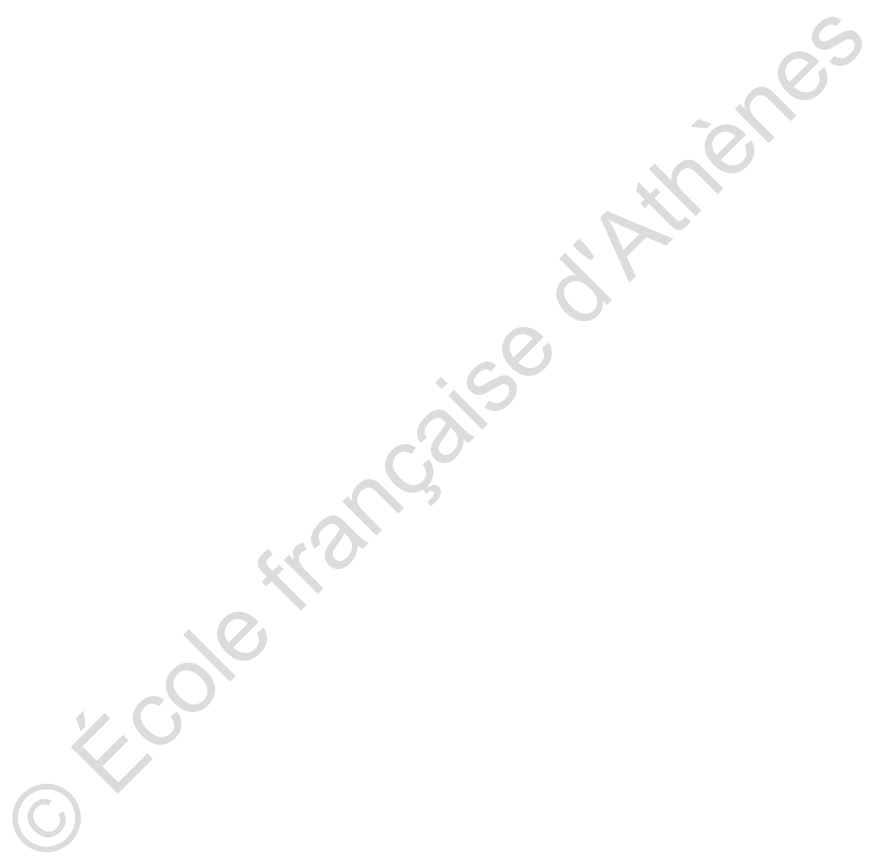




\section{AVIS AUX LECTEURS}

\section{Chronique en ligne}

Partageant une longue tradition, l'École française d'Athènes et la British School at Athens diffusent auprès de la communauté scientifique le résultat de l'activité archéologique conduite en Grèce et dans certaines régions du monde hellénique. Depuis 1920, l'École française d'Athènes consacre une partie du Bulletin de correspondance hellénique à la chronique des travaux archéologiques réalisés en Grèce, à Chypre et, selon un rythme bisannuel, dans le Bosphore cimmérien. De son côté, la British School at Athens compile un bilan annuel similaire, Archaeology in Greece, publié en association avec la Society for the Promotion of Hellenic Studies comme partie constitutive des Archaeological Reports depuis 1955. Chacune des deux institutions avait un double défi à relever : faire face à une documentation croissante, d'une part; utiliser des outils plus performants pour mieux faire circuler l'information scientifique et en permettre une meilleure utilisation, d'autre part. — L'École britannique a accepté sans hésitation le projet d'un programme commun que lui a proposé l'École française d'Athènes et les deux institutions ont décidé d'unir leurs efforts, pour proposer depuis la fin de l'année 2009 une Chronique des fouilles en ligne consultable sur http://chronique.efa.gr.

Outre les articles relatifs à des opérations de terrain ou relevant de l'archéométrie, le second fascicule du $B C H$ ne comprend donc plus désormais que les " Rapports sur les travaux de l'École française d'Athènes " proposés par les responsables de missions ou de programmes.

\section{AVIS AUX AUTEURS}

Depuis la parution du $B C H 130$ (2006), les tirages à part sont fournis aux auteurs sous format électronique et sont uniquement destinés à une utilisation privée. L'École française d'Athènes conserve le copyright sur les articles, qui ne peuvent donc être mis en accès libre sur quelque base de données ou par quelque portail que ce soit. — L'ensemble de la livraison sera disponible sur le portail Persée trois ans après sa parution (www.persee.fr). 


\section{SOMMAIRE DE LA LIVRAISON}

Laetitia Phialon

Une place pour l'artisanat mycénien? Remarques sur les espaces de production

et d'activités artisanales à l'Helladique Récent.

Natacha TRIPPÉ

Une lettre d'époque classique à Thasos.

Patrice HАMоN

Etudes d'épigraphie thasienne, IV. Les magistrats thasiens du IVe s. av. J.-C.

et le royaume de Macédoine.

Athanasios Tziafalias, Laurence Darmezin

Dédicaces d'affranchis à Larissa (Thessalie).

Benedetto Bravo, Aleksander Wolicki

Un katadesmos du banquier Pasiôn (SEG LIII 256)

$211-236$

Nathan BADOud

Note sur trois inscriptions mentionnant des Rhodiens morts à la guerre. Contribution à

l'étude des relations entre Rhodes et Rome à la fin du IVe s. av. J.-C.

Rachel NoueT

La " déesse au serpent " de Délos et l'aménagement des Propylées déliens

à l'époque classique.

Frédéric Herbin, François QueYrel

Les monuments attalides du Dromos à Délos (I) : la "base des Galates"

Pavlos Karvonis, Jean-Jacques Malmary

Les mezzanines déliennes : étude technique et contexte archéologique. $321-344$

Nathan Badoud, Myriam Fincker, Jean-Charles Moretti

Les monuments érigés à Délos et à Athènes en l'honneur de Ménodôros, pancratiaste et lutteur. $345-416$

Alain Bouet, Enora Le QuÉRÉ

Les thermes impériaux de Délos : l'infrastructure publique d'une ville ö $\delta \eta \lambda \lambda_{\diamond}$ ? $417-462$

Ludovic THÉLY

Inscriptions d'Amathonte XI. Un autel en l'honneur de Ptolémée X

et Bérénice III découvert aux abords Sud-Ouest de l'agora 463-484 


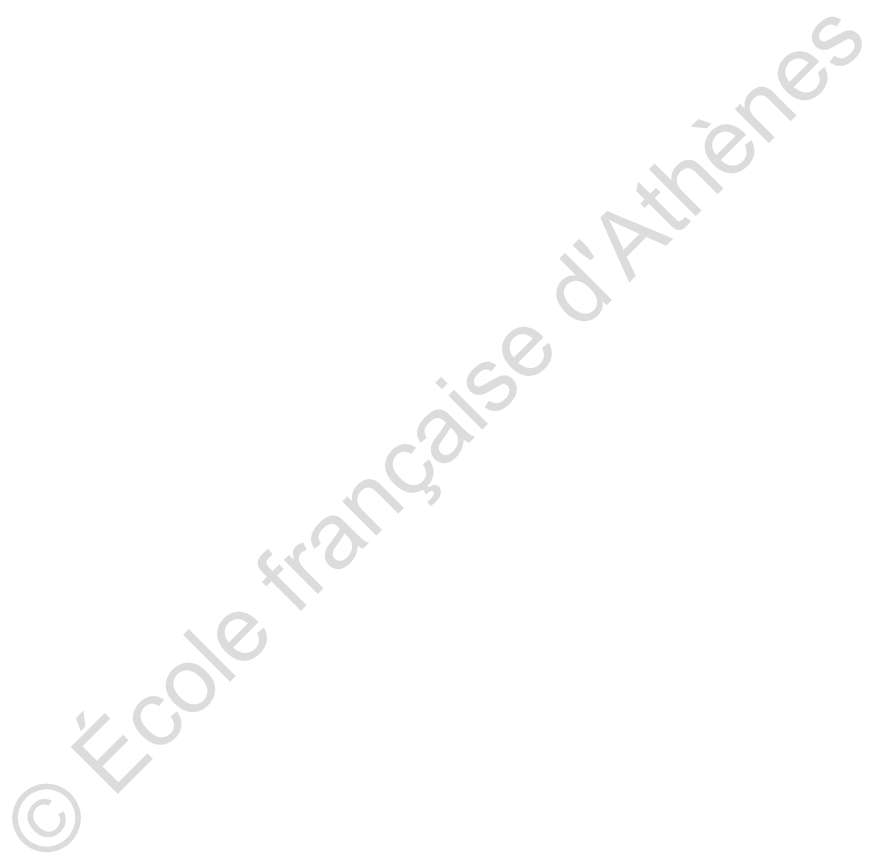




\title{
Une place pour l'artisanat mycénien? Remarques sur les espaces de production et d'activités artisanales à l'Helladique Récent
}

\author{
Laetitia Phialon
}

RÉsumé Cet article se propose d'examiner les espaces de production et d'activités artisanales dans le monde mycénien. On s'intéresse aux structures fixes - telles que les fours artisanaux - et aux dépôts d'outils, d'objets semi-finis ou de matériaux bruts découverts en contexte de l'Helladique Récent. Alors que certaines activités artisanales, comme le travail de l'ivoire, se concentrent sur des sites palatiaux tels que Mycènes et Thèbes à l'HR III B, la production céramique est attestée par la découverte de fours dans différents habitats, tout au long de l'HR. Les espaces de travail étaient bien intégrés à l'habitat mycénien, même là où des activités métallurgiques sont attestées, comme à Tirynthe. Les équipements artisanaux demeurent toutefois le plus souvent incomplets en Grèce mycénienne. Cette observation conduit à se pencher sur le caractère et la spécificité des ateliers identifiés.

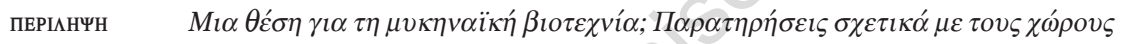

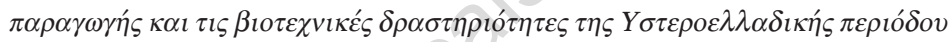

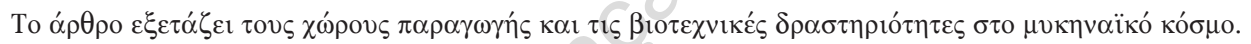

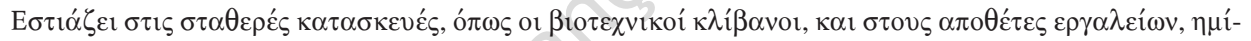

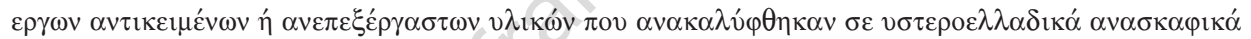

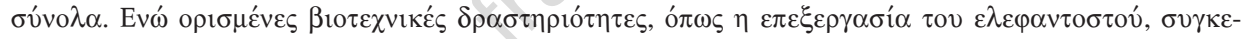

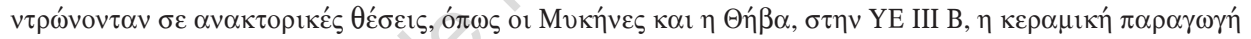

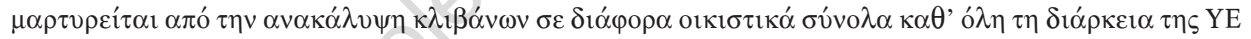

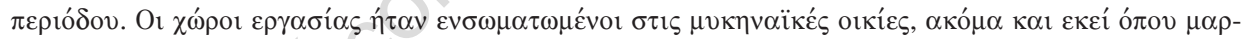

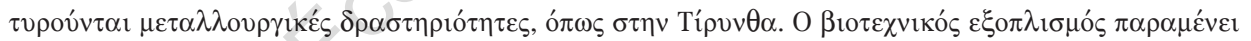

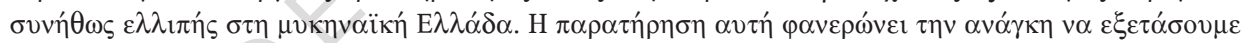

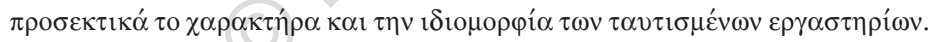

SUMMARY Room for Mycenaean craftsmanship? Remarks on production spaces and craft activities in the Late Helladic period

This article examines the production spaces and craft activities of the Mycenaean world. It focuses on fixed structures such as artisanal kilns and tool deposits, semi-worked items and raw materials uncovered in Late Helladic context. While some craft activities such as ivory work were concentrated at palace sites such as Mycenae and Thebes in LH IIIB, pottery production throughout the Late Helladic period is attested by potters' kilns in several settlements. Work spaces were well integrated into Mycenaean settlements, even where metallurgical activities are attested, for instance at Tiryns. However, craft assemblages from Mycenaean Greece are mostly incomplete, so it makes sense to focus on the nature and specific characteristics of the workshops that have been identified. 


\section{À PROPOS DE L'AUTEUR}

L. Phialon, membre de l'École française d'Athènes.

\section{NOTE LIMINAIRE}

L'essentiel de cet article a été présenté lors de la table ronde intitulée Le rôle de l'artisanat dans la genèse et la structuration des agglomérations, organisée par G. Pagès et R. Clotuche, à la Maison de l'Archéologie et de l'Ethnologie de Nanterre, le 2 octobre 2014, que je remercie pour cette rencontre.

\section{ABRÉVIATIONS BIBLIOGRAPHIQUES}

ÅкеRSTRÖм 1987 = А̊. А̊кеRSTRÖм, Berbati. 2, The Pictorial Pottery, Skrifter Utgivna av Svenska Institutet i Athen $4^{\circ}$, XXXVI:2.

Alberti et al. 2012 = E. Alberti, V. L. Aravantinos, M. Del Freo, I. Fappas, A. Papadaki, Fr. Rougemont, "Textile Production in Mycenaean Thebes. A First Overview ", dans M.-L. Nosch, R. Laffineur (éds), KOSMOS. Jewellery, Adornment and Textiles in the Aegean Bronze Age, Proceedings of the 13th International Aegean Conference, University of Copenhagen, Danish National Research Foundation's Centre for Textile Research, 21-26 April 2010, Aegaeum 33, p. 87-105.

Brysbaert, Vetters 2013 = A. Brysbaert, M. Vetters, « A Moving Story about Exotica: Objects' Long-Distance Production Chains and Associated Identities at Tiryns, Greece ", OpAth 6, p. 175-210.

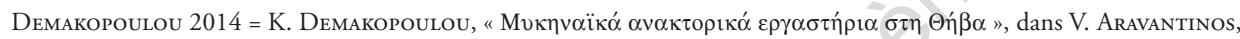

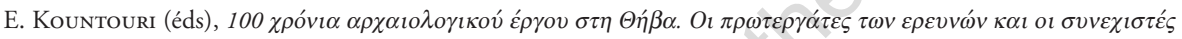

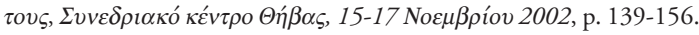

DMic 1 et 2 = F. Aura Jorro, F.R. Adrados, Diccionario Griego-Español, Diccionario Micénico, vol. I (1985) et vol. II (1993).

Documents $^{2}=$ M. Ventris, J. Chadwick, Documents in Mycenaean Greek, $2^{\mathrm{c}}$ édition (1973).

Evely 2000 = R. D. G. Evely, Minoan Crafts: Tools and Techniques, SIMA 92/2.

Gillis et al. 1997 = C. Gillis, Ch. Risberg, B. Sjöberg (éds), Trade and Production in Premonetary Greece. Production and the Craftsman. Acquisition and Distribution of Raw Materials and Finished Products, Proceedings of the 4th and 5th International Workshops, Athens 1994 and 1995.

HASAKI 2002 = E. HASAKI, Ceramic Kilns in Ancient Greece: Technology and Organization ofCeramic Workshops, PhD, University of Cincinnati.

Laffineur, Betancourt 1997 = R. Laffineur, Ph. Betancourt (éds), TEXNH I-II. Craftsmen, Craftswomen and Craftsmanship in the Aegean Bronze Age, Proceedings of the 6th International Aegean Conference, Philadelphia, 18-21 April 1996, Aegaeum 16.

PNI = C.W. BlEgen, M. Rawson, The Palace of Nestor at Pylos in Western Messenia. I. The Buildings and their Contents (1966).

Poursat 1977 = J.-Cl. Poursat, Les ivoires mycéniens. Essai sur la formation d'un art mycénien, BEFAR 230.

PTT = E. L. Bennett, J.-P. Olivier, The Pylos Tablets Transcribed, Incunabula Graeca 51 (1973).

Quartier Mu III = J.-Cl. Poursat, Artisans minoens : les maisons-ateliers du Quartier Mu. Fouilles exécutées à Malia. Le Quartier Mu III, ÉtCrét 32 (1996).

Rahmstorf 2008 = L. Rahmstorf, Kleinfunde aus Tiryns. Terrakotta, Stein, Bein und Glas/Fayence vornehmlich aus der Spätbronzezeit, Tiryns XVI.

SAMPSON 1985 = A. SAMPSON, "La destruction d'un atelier palatial mycénien à Thèbes ", BCH 109, p. 21-29.

Symeonoglou 1973 = S. Symeonoglou, Kadmeia I. Mycenaean Finds from Thebes, Greece. Excavation at 14 Oedipus st., SIMA 35

Tournavitou 1988 = I. Tournavitou, "Towards an Identification of a Workshop Space », dans E. B. French, K. Wardle (éds), Problems in Greek Prehistory, Papers Presented at the Centenary Conference of the BSA, Manchester April 1986, p. $447-467$.

Tournavitou 1995 = I. Tournavitou, The 'Ivory Houses' at Mycenae, BSA supplementary 24.

Tournavitou 1997 = I. Tournavitou, "Jewellers' Moulds and Jewellers' Workshops in Mycenaean Greece. An Archaeological Utopia », dans Gillis et al. 1997, p. 209-256.

\section{BCH 139-140 (2015-2016)}


Alors que les produits finis témoignent d'un artisanat mycénien riche et varié, rares sont les espaces de production et d'activités artisanales du Bronze Récent (ca. 1700/16001100 av. J.-C.) bien identifiés sur le continent grec. Ce contraste demeure peu expliqué malgré la découverte, en Grèce mycénienne, de fours artisanaux ainsi que d'assemblages de mobilier spécifique comprenant des ébauches, de la matière première ou des outils, qui servent de critères déterminants pour identifier de tels espaces ${ }^{1}$. C'est pourquoi on s'intéressera, dans cet article, aux contextes de l'Helladique Récent qui ont livré des structures et des dépôts susceptibles d'attester in situ une production artisanale. Il s'agira en premier lieu d'identifier les lieux et les espaces de productions céramique et métallurgique ou encore ceux du travail de l'ivoire. On se penchera ensuite sur les traces archéologiques de production textile laissées in situ.

Une des raisons qui pourraient expliquer la rareté des espaces reconnus de production et d'activités artisanales est le caractère isolé ou incomplet des équipements mis au jour. Il conviendra d'examiner les rapports qu'entretiennent ces espaces avec le reste de l'agglomération et, dans certains cas, de se pencher sur leur proximité avec le rempart afin de mieux comprendre leur intégration au sein de l'habitat. Une attention particulière sera portée à leur position dans le site et au caractère des bâtiments qui abritaient de telles activités.

L'identification d'espaces de production artisanale sera l'occasion de revenir sur les questions de définition et de critères d'identification des ateliers. Si la présence même d'un four indique l'existence d'un espace de production, on peut se demander si tout espace de production correspond à un atelier. Un atelier peut être considéré comme un espace bâti qui abrite des activités artisanales, reconnues notamment par la présence de structures spécifiques et d'outils ${ }^{2}$, et qui se distingue par son caractère permanent des simples places de travail ${ }^{3}$. Les places de travail artisanal devront également être différenciées des espaces réservés pour le matériel en attente d'être fini ou monté.

1. Voir P. Darcque, L'habitat mycénien. Formes et fonctions de l'espace bâti en Grèce continentale à la fin du II millénaire avant J.-C., BEFAR 319 (2005), p. 286 : "Ce matériel doit comprendre dans le cas idéal, de la matière première, des outils, des chutes, des ébauches, des ratés ou des scories, ainsi que des objets du même type regroupés en dépôt ". Pour des critères similaires évoqués pour la Crète minoenne, voir R. D. G. Evely, "Minoan Craftsmen: Problems of Recognition and Definition ", dans E. B. French, K. A. Wardle (éds), Problems in Greek Prehistory (1988), p. 408-409; L. Platon, "Ateliers palatiaux minoens : une nouvelle image ", BCH 117 (1993), p. 105.

2. Voir Tournavitou 1988 : l'auteur traite des aspects touchant divers domaines (architecture, céramique, aménagements, outils, matériel travaillé, relation avec le centre administratif), voir p. 448-449; les structures fixes sont regroupées sous le groupe B des ateliers, voir p. 451. Les traits architecturaux et la position topographique seront ici discutés mais ne sont pas des critères déterminants pour l'identification de nos espaces.

3. Pour une distinction entre ateliers domestiques et ateliers permanents, voir Tournavitou 1988, p. 447. L'auteur emploie le terme "place de travail " (workplace) dans sa définition d'ateliers domestiques. 
Mais la place de l'artisanat en Grèce mycénienne sera également traitée selon une approche géographique. Des établissements ou des régions ont pu, en effet, se distinguer par la diversité des activités artisanales menées au cours de l'Helladique Récent, contrairement à d'autres qui semblent s'être concentrés sur un seul type de production. Il conviendra donc de comparer la densité des espaces de production et activités artisanales à l'échelle du site comme au niveau régional. On gardera à l'esprit que notre recherche est de nature archéologique mais que, pour la période palatiale mycénienne, nos données devront être confrontées à l'apport des textes en linéaire B.

Il s'agira enfin de comprendre si l'implantation d'espaces de production au sein des habitats mycéniens répond à une logique d'installation, si elle s'inscrit dans un développement graduel de l'habitat ou si elle fait partie d'une réorganisation de ce dernier. Enfin, on n'écartera pas l'hypothèse que le choix de leur emplacement ait été dicté par des exemples antérieurs de l'Helladique Moyen ni la possibilité que l'expérience minoenne ait pu inspirer un modèle continental.

\section{LES FOURS ARTISANAUX EN CONTEXTE MYCÉNIEN}

\section{1. Des STRuCtures INTÉgrées À l'habitat}

La découverte de fours artisanaux constitue un critère de reconnaissance fiable d'espaces de production artisanale. Ces structures fixes, contrairement au mobilier, n'ont pas pu être déplacées pour être gardées dans un endroit différent du lieu de production. Sur la base de travaux de synthèse ${ }^{4}$, on recense la découverte de fours destinés à la production céramique et métallurgique en contexte de l'Helladique Récent dans onze sites au moins (fig. I), qui se concentrent sur deux régions : la première en Argolide (Berbati, Tirynthe et Asinè); la seconde en Thessalie (Volos, Dimini, Velestino-Pherai). La distribution de fours artisanaux dans d'autres régions de Grèce continentale se révèle plus éparse (Pylos, Kirrha, Aigeira, Thèbes, Kynos/Livanatès-Pyrgos). Les fours de potier mis au jour en Grèce continentale sont attribués à des phases qui s'échelonnent de l'HR I-II à l'HR III C (annexe 1). Leur usage couvre donc tout l'Helladique Récent, à la différence des fours métallurgiques tous datés de l'HR III.

La concentration de fours artisanaux en Argolide au cours de l'HR III est renforcée par la découverte de plusieurs d'entre eux à Tirynthe (fig. 2), sur le côté occidental de la cita-

4. A. Hansen Streily, Bronzezeitliche Töpferwerkstätten in der Ägäis und in Westanatolien, Diss., Universität Mannheim (2000); Hasaki 2002; P. Darcque (n. 1), p. 167-170; J.-S. Gros, J. Zurbach, « Espaces de la production céramique et spécialisation artisanale entre Bronze et Fer en Égée », dans A. Esposito, G. M. SANIDAs (éds), "Quartiers » artisanaux en Grèce ancienne. Une perspective méditerranéenne (2012), p. 112 , n. 14. 


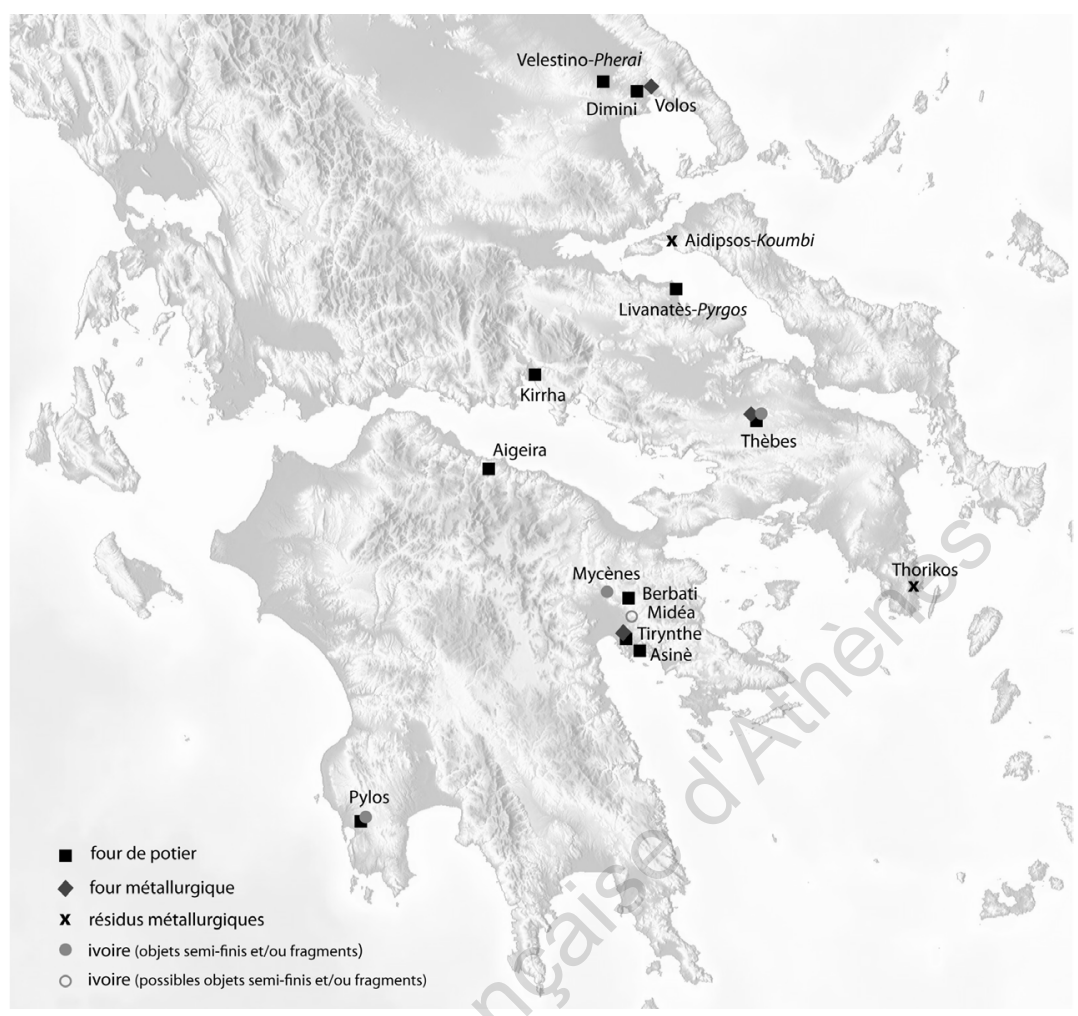

Fig. I - Carte des habitats de l'Helladique Récent mentionnés dans le texte (pour les références bibliographiques, voir annexe 1 ; fond de carte, d'après map-for-free, 2014).

delle basse (Unterburg), près du mur de fortification. Il s'agit de deux fours métallurgiques ${ }^{5}$ et d'un four de potier 6 , qui appartiennent à des phases d'occupation successives allant de l'HR III B à l'HR III C récent. Le type de production lié à deux autres fours mis au jour dans la citadelle basse, l'un de l'HR III B2 et l'autre de l'HR III C, n'est pas déterminé7 tandis que la datation d'un sixième four artisanal découvert sur la citadelle intermédiaire (Mittelburg) et identifié comme un four de potier mycénien n’est pas précisée ${ }^{8}$.

5. K. Kilian, "Ausgrabungen in Tiryns 1982/83. Bericht zu den Grabungen », $A A$ 1988, p. 126, 135, fig. 31-32 (R 210, HR III B1); id., "Ausgrabungen in Tiryns 1976. Bericht zu den Grabungen", $A A$ 1978, p. 459-460, fig. 14 (R 106, HR III C récent).

6. Id., «Ausgrabungen in Tiryns 1978-1979. Bericht zu den Grabungen ", AA 1981, p. 165-166, fig. 14 et 18 (à l'Ouest de R 119, HR III C ancien); Rahmstorf 2008, p. 256.

7. K. Kilian (n. 5, 1988), p. 117, 123, fig. 19 (Bau II), p. 121, fig. 21 (R 76, HR III C ancien).

8. H. DragendorfF, «Tiryns. Vorbericht über die Grabungen 1913 ", AM 38 (1913), p. 338-341, fig. 3. Les fours de potier sont étudiés par S. Prillwitz que je remercie pour les renseignements apportés. Toute erreur ou omission relève de ma responsabilité. 


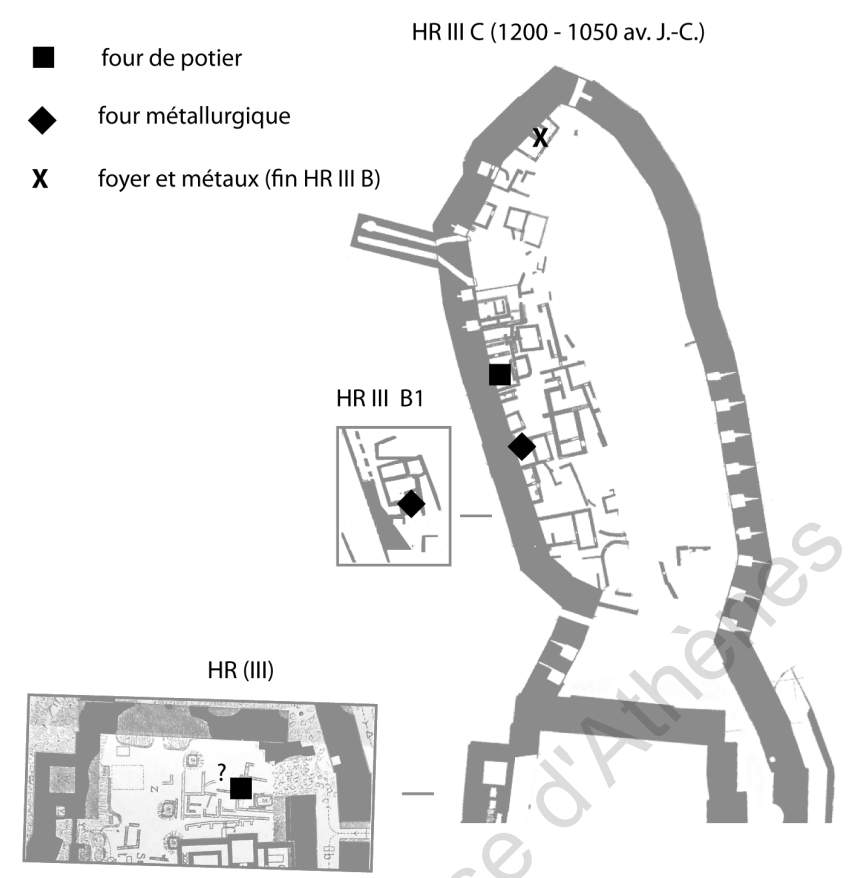

Fig. 2 - Fours artisanaux à Tirynthe, emplacement supposé (plan de Tirynthe d'après : U. Damm-Meinhardt, T. MüHLennRuch, Baubefunde und Stratigraphie der Unterburg und des nordwestilchen Stadtgebiets (Kampagnen 1976 bis 1983), Tiryns XVII 3 (2013), pl. 2.; Rahmstorf 2008, pl. 102; d'après H. Dragendorff [n. 8]).

L'existence d'un atelier dans la pièce 210 à l'HR III B1 est certaine', comme l'attestent, pour la première phase d'occupation, des restes de scories et des résidus de bronze ainsi qu'un fragment de creuset trouvés conjointement avec le four. Durant la première phase, cet atelier s'étendait certainement à la pièce 214 où se trouvaient un foyer et un mobilier varié incluant un fragment de moule en terre et un morceau de bleu égyptien ${ }^{10}$, et à la pièce 215, si on y associe les résidus de bronze et un fragment de creuset recueillis à un niveau plus haut ainsi qu'un lingot de bronze dissimulé dans le mur Sud de cette pièce $^{11}$. Durant la seconde phase d'occupation, le four était vraisemblablement toujours en usage puisque des restes de bronze et les fragments de deux creusets ont, entre autres, été mis au jour dans l'espace ouvert situé au Sud de cette pièce ${ }^{12}$.

9. Rahmstorf 2008, p. 271-272; Brysbaert, Vetters 2013, p. 183-190.

10. Rahmstorf 2008, p. 271 ; Brysbaert, Vetters 2013, p. 185. Les perles en pâte de verre trouvées dans l'espace ouvert au Sud-Ouest du foyer ne sont toutefois pas associées aux activités artisanales par les auteurs, mais pourraient éventuellement être interprétées comme perles votives.

11. Rahmstorf 2008, p. 270. La pièce était peut-être pourvue d'un foyer.

12. Ibid., p. 272; Brysbaert, Vetters 2013, p. 186. 
À la présence des fours s'ajoute celle de foyers, qui ont pu servir à la fonte ou à l'alliage de métaux, dans la citadelle basse de Tirynthe. Dans l'aire Nord-Ouest, deux foyers assignés à la fin de l'HR III B sont respectivement liés au travail du cuivre et du plomb. Le premier a été découvert dans la pièce 78a du bâtiment XI, qui a livré un abondant mobilier. Sans doute un travail de finition, comme l'ornement des objets de valeur, était entrepris dans le bâtiment identifié comme un atelier par A. Brysbaert et M. Vetters ${ }^{13}$ : des résidus d'alliage de cuivre et un fragment de bronze ont été retrouvés dans le foyer, ainsi que de l'or ${ }^{14}$. Le second foyer mentionné ci-dessus, situé plus au Sud, est associé à des résidus de plomb, des éléments et objets en plomb ainsi qu'à un fragment de creuset dégagés à l'extérieur d'une maison ${ }^{15}$. Un troisième foyer plus récent, situé aussi dans l'aire Nord-Ouest, au Sud d'une pièce occupée plus tard, à l'HR III C, a peut-être également servi au travail de métaux, étant donné qu'un morceau de galène et un fragment de creuset ont été mis au jour à proximité ${ }^{16}$. Alors que le bâtiment XI a certainement abrité un atelier, les deux autres exemples fournissent des indices plus ténus pour une telle identification. Ils suggèrent, en revanche, que des métaux ont pu être travaillés, successivement, à divers endroits de la citadelle basse ${ }^{17}$.

L'usage de fours au cours de l'HR III C à Tirynthe, c'est-à-dire après l'effondrement des palais mycéniens, doit également être souligné ${ }^{18}$. Plusieurs ouvertures faites dans le mur de fortification de la phase précédente ont été fermées, ce qui devait encore mieux protéger les activités de natures diverses menées à sa proximité. Des espaces de production et de stockage domestique, et d'autres à vocation vraisemblablement cultuelle pouvaient se trouver à proximité. Par exemple, la pièce 106 - qui comprenait un four métallurgique de l'HR III C récent - a livré des restes de plomb, mais aussi trois pithoi au moins trouvés in situ et un cratère qui provenait sans doute d'un étage supérieur ${ }^{19}$, tandis que deux

13. A. Brysbaert, M. Vetters, "Practicing identity: a crafty ideal? ", Mediterranean Archaeology and Archaeometry 10.2 (2010), p. 32-33; Brysbaert, Vetters 2013, p. 195-199. Le nombre de lames et d'éclats d'obsidienne qui, emmanchés, peuvent avoir servi d'outils est élevé.

14. K. Kilian (n. 5, 1988), p. 111, n. 14; Rahmstorf 2008, p. 240-241; Brysbaert, Vetters 2013 , p. 195-199.

15. Rahmstorf 2008, p. 248-249 (au Nord de R 3 du bâtiment III).

16. Ibid., p. 245 (Kammer 14, HR III C moyen/Fortgeschritten); voir K. Kilian (n. 5, 1988), fig. 10b à p. 112.

17. En ce qui concerne l'HR III B2, le caractère artisanal de la pièce R 10 du bâtiment I, située dans l'aire Ouest, est discuté. Selon K. Kilian (n. 6), p. 176, les couches de cendres et le morceau de galène soutiennent cette identification, contrairement à RAHMSTORF 2008, p. 252-253, qui considère que ces éléments ne sont pas suffisants pour prouver l'existence d'activités métallurgiques. Les couches de cendres sont vraisemblablement dues à la destruction de cet horizon. Selon BrysBaert, VetTers 2013, p. 192, il s'agit d'une pièce de transit; la galène a en outre été ré-identifiée comme hématite.

18. Pour la dernière phase de la citadelle (ca. 1200-1050 av. J.-C.), voir http://www.zaw.uni-heidelberg.de/ hps/ufg/tiryns/Ti_theSite.html, fig. 5.

19. K. Kilian (n. 5, 1978), p. 459-460, fig. 16. 
pièces voisines de celles des fours comprenaient un foyer ${ }^{20}$ et une troisième pièce trois statuettes complètes et les fragments d'autres exemplaires recueillis sur et près d'un banc ${ }^{21}$.

L'habitat de Kirrha, en Phocide, se distingue également par l'usage successif de fours, mais vraisemblablement destinés cette fois à la production céramique, sur une période allant de l'HM III-HR I ${ }^{22}$ à l'HR III ${ }^{23}$, sur le côté oriental de l'habitat préhistorique. Dans les deux cas, on relève un phénomène de continuité évident dans le choix de leur emplacement, et donc dans celui de la zone réservée à l'espace de production artisanal au sein de l'habitat. Mais la comparaison s'arrête là. Tirynthe est, en effet, un site palatial à l'HR III A-B, ce qui n'est pas le cas de Kirrha, dont l'habitat perd vraisemblablement de l'importance au cours de l'Helladique Récent. On peut dès lors se demander quelles étaient l'ampleur de la production et la qualité de la céramique produite à Kirrha durant l'HR III, en particulier face à celles de la période mésohelladique (2050/2000$1700 / 1600$ av. J.-C.), lorsque l'habitat était plus substantiel.

Le même type d'interrogations se pose pour la période post-palatiale. Le site fortifié d'Aigeira en Achaïe, notamment, comprend un four de potier daté de l'HR III C, situé à moins de 7 mètres du mur ${ }^{24}$. Son usage est contemporain de celui de pithoi découverts in situ à quelques mètres de distance ${ }^{25}$. Il se trouve en outre près de vestiges interprétés comme

20. Ibid., p. 459 (R103, R104).

21. Ibid., p. 461 (R110a, " in die fortgeschrittene SH III C-Periode »), p. 464 (R 110, " entwickelt III C »), fig. 17 et 20. Deux des statuettes ont été trouvées devant un banc, et une autre sur ce même banc rehaussé. À la première phase appartiennent aussi les fragments de cinq autres statuettes. Pour des pièces considérées comme cultuelles (R 117, R 110, R 100a, R 119), voir Rahmstorf 2008, p. 264. Pour un lien entre les sanctuaires et les productions artisanales, voir B. MonTECCHI, "Santuari micenei e produzione artigianale: i casi di Pilo, Micene, Tirinto e Dimini ", Annuario 84 (2006), p. 161-190, pour Tirynthe, voir p. 171-175, 180.

22. Les deux fours en forme de fer à cheval sont datés de l'HM III-HR I, celui de plan circulaire de

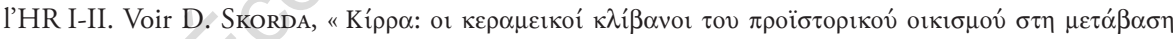

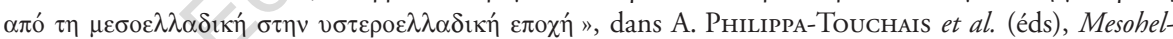
ladika. La Grèce continentale au Bronze Moyen (2010), p. 651-668; voir aussi D. Hatzimilahi-SKorda,

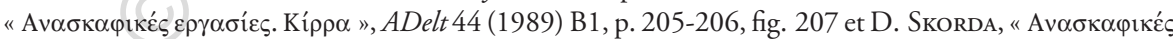

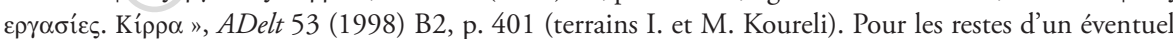
four de potier HM (terrain D. Kollia), certainement aussi situé dans la partie Est de la magoula, voir

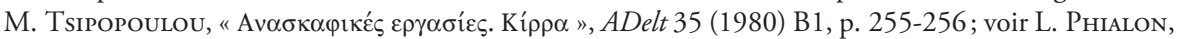
L'émergence de la civilisation mycénienne en Grèce centrale, Aegaeum 32 (2011), p. 47.

23. Pour deux petits fours HR III, très probablement des fours de potier, voir D. SKorda, J. ZurbaCH, «Kirrha (Phocide) », BCH 134 (2010), p. 546. http://www.chronique.efa.gr/index.php/fiches/voir/1361/

24. W. Alzinger, S. Deger-Jalkotzy, E. Alram-Stern, "Aigeira-Hyperesia und die Siedlung Phelloë in Achaia (I) ", Klio 67 (1985), p. 402, fig. 10.

25. E. Alram-Stern, "Aigeira - Acropolis: The Stratigraphy ", dans S. Deger-Jalkotzy, M. Zavadil (éds), LH IIIC Chronology and Synchronisms, Proceedings of the International Workshop Held at the Austrian Academy of Sciences at Vienna, May 7th and 8th, 2001 (2003), p. 15-21. Voir aussi http://www.oeai.at/ index.php/317.html. 
des restes possibles de forge. Espaces de production artisanale et réserves alimentaires ont donc probablement coexisté non loin les uns des autres. Peu de choses peuvent être dites, en revanche, sur l'emplacement du four de potier de Kynos (Livanatès-Pyrgos) dans l'habitat de l'HR III C moyen ${ }^{26}$, ni sur celui de Velestino, localisé sur le côté Sud/Sud-Est de la magoula Bakali et daté également de l'HR III C ${ }^{27}$.

En somme, les fours artisanaux ont pour la plupart été découverts près ou au sein d'un espace bâti (Berbati, fig. 3), situé en bordure (Kirrha) ou au cœur de l'habitat mycénien (Thèbes, fig. 4), qui peut être, selon les sites, fortifié (Tirynthe, Aigeira). L'usage des fours est le plus souvent contemporain de celui des bâtiments ou des constructions alentour, quelle que soit la phase HR à laquelle ils appartiennent, et cela même si, dans le cas de Pylos, le four de l'HR I-II est plus ancien que la phase d'occupation principale du site à

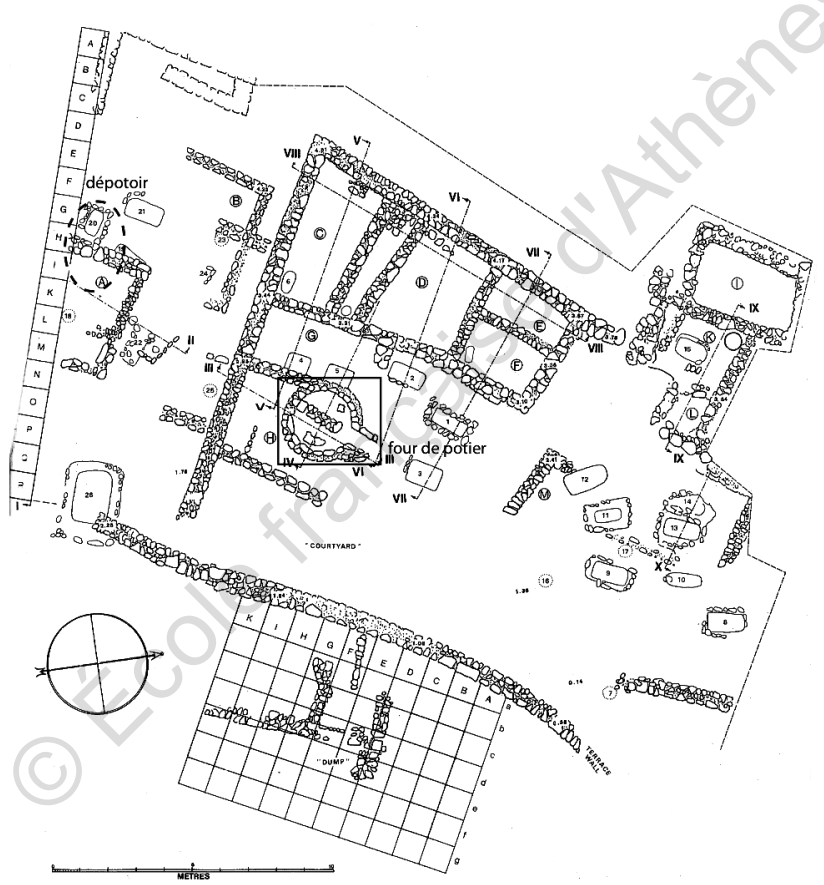

Fig. 3 — Le Quartier du Potier à Berbati (plan d'après ÅKerströм 1987).

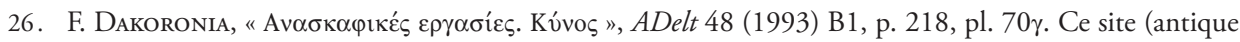
Kynos) se trouve au lieu-dit Pyrgos, près de Livanatès. Des traces d'activités métallurgiques y sont également signalées, liées à la présence possible d'un autre four, voir aussi F. DAKoroniA, "The Transition from Late Helladic III C to the Early Iron Age at Kynos », dans S. Deger-Jalkotzy, M. ZavadiL (éds), LH IIIC Chronology and Synchronisms I (2003), p. 38.

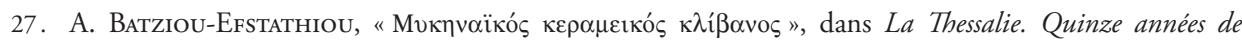
recherches archéologiques, 1975-1990. Bilans et perspectives (1994), p. 217, fig. 3 (terrain M. G. Saranti). 


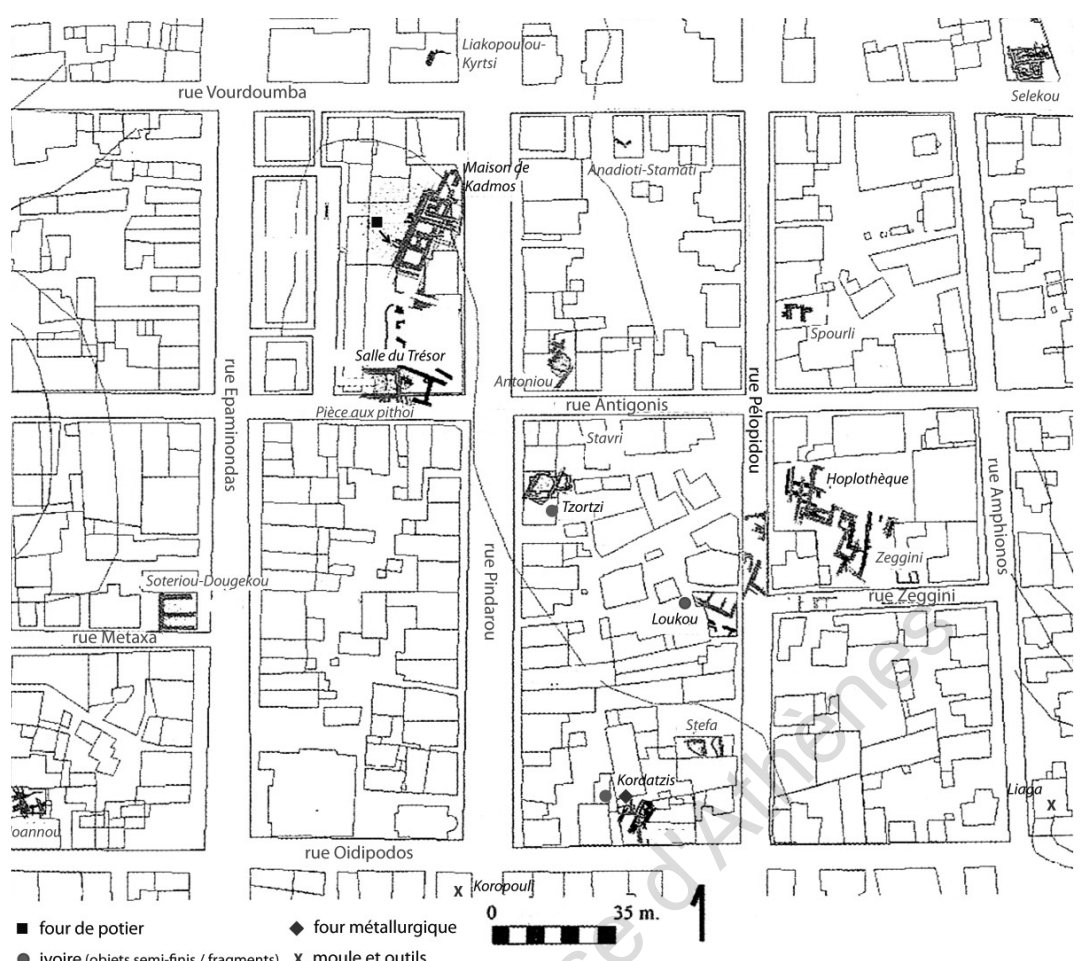

Fig. 4 - Fours artisanaux et dépôts spécifiques à Thèbes (plan de la Cadmée de Thèbes, fond de carte, d'après A. Dakouri-Hild [n. 50], p. 102, fig. 11).

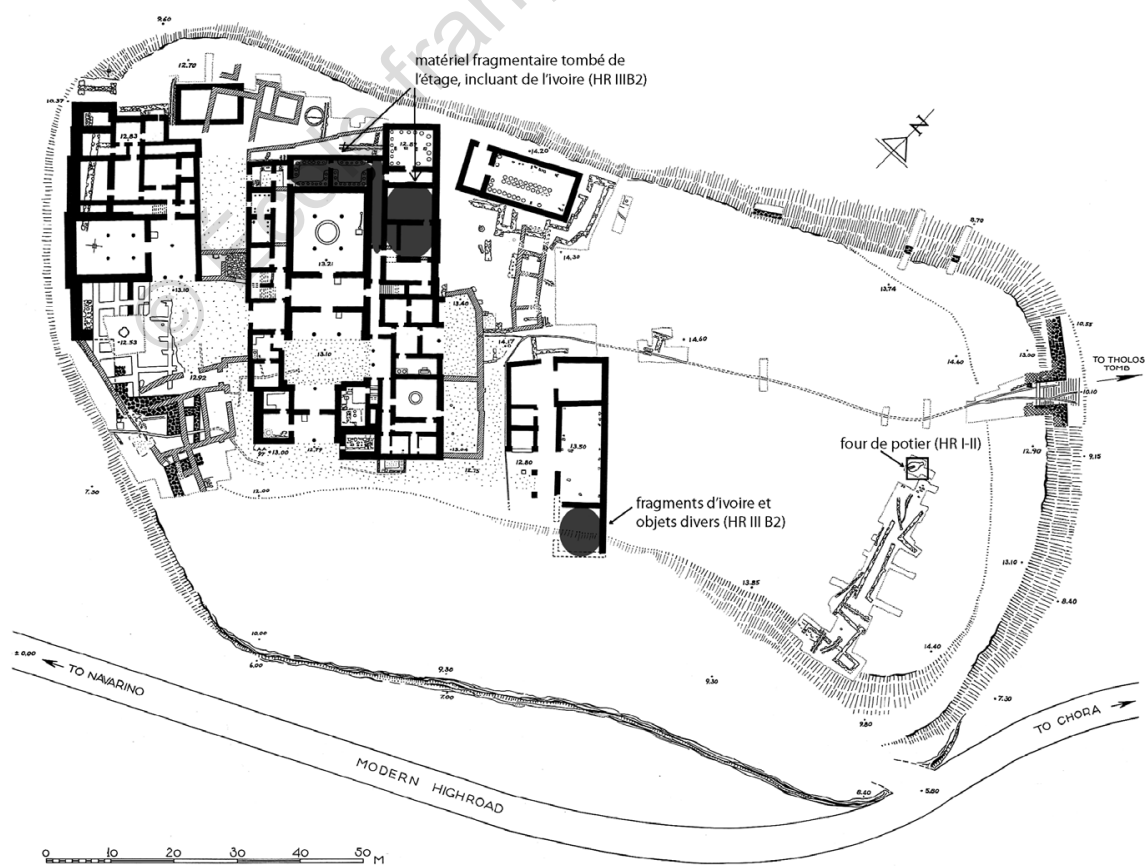

Fig. 5- Four de potier et dépôts d'ivoire à Pylos (plan de Pylos, d'après PN I, fig. 416). 
l'HR III B (fig. 5). Le four de Pylos, situé au Sud-Est du palais, n'est pas, à proprement parler, compris dans un espace bâti, mais se trouve au Nord de constructions contemporaines dotées d'un mobilier varié qui inclut, certes, des outils tels que deux poinçons en os mais aussi, par exemple, des pointes de flèche en bronze et en pierre ${ }^{28}$.

\section{2. Des Structures À Caractère SOUvent ISOlÉ}

Alors que les exemples observés ci-dessus tendent à montrer que les espaces de production artisanale identifiés par la présence de fours sont bien intégrés au sein de l'habitat contemporain, le caractère isolé des fours de potier a été souligné par différents chercheurs $^{29}$. Les raisons évoquées sont le manque de structures complémentaires associées à ces fours ou encore l'absence d'outils mis au jour dans les mêmes espaces. Dans le cas présent, l'histoire du site et de l'espace étudié est d'autant plus importante qu'elle peut expliquer l'absence de matériel associé aux fours ${ }^{30}$. Aucun dépôt d'outils ne représente l'équipement complet d'un artisan, qui peut seulement être reconstitué de manière théorique ${ }^{31}$, même dans le cas de Tirynthe où des ateliers ont été identifiés. Outils et objets ont pu être emportés lors d'un abandon délibéré des structures.

On ne trouve pas de bassin ni de tour de potier à proximité des fours destinés à la production céramique en Grèce mycénienne, contrairement à ce que l'on constate en Crète de l'âge du Bronze ${ }^{32}$ ou dans le cas idéal d'un atelier de potier moderne ${ }^{33}$. De toute manière, le tour de potier est exceptionnellement représenté en contexte mycénien ${ }^{34}$. La

28. Il s'agit du Belvedere area, voir C. W. Blegen et al., The Palace of Nestor at Pylos in Western Messenia. III. Acropolis and Lower Town. Tholoi, Grave Circle, and Chamber Tombs. Discoveries outside the Citadel (1973), p. 19-20 (four), 24 (objets), fig. 109, pour le plan, voir fig. 302. À l'HR II, le site de Pylos est principalement connu pour ses tombes situées à quelque distance de la colline.

29. Hasaki 2002, p. 215; P. Darcque (n. 1), p. 169; J.-S. Gros, J. Zurbach (n. 4), p. 112.

30. L'importance de l'histoire du site a été soulignée par Tournavitou 1988, p. 453.

31. Il comprendrait, pour le travail de l'or, des creusets, des moules, des ciseaux et des marteaux, des poinçons et des aiguilles, des petits couteaux, des outils pour graver, des pinces, de la pierre ponce, de la cire et de la résine. Voir E. Konstantinidi-Syvridi et al., "Goldworking Techniques in Mycenaean Greece (17th/16th-12th century BC): some New Observations ", dans H. Meller, R. Risch, E. PernickA (éds), Metalle der Macht - Frühes Gold und Silber, 6. Mitteldeutscher Archäologentag vom 17. bis 19. Oktober 2013 in Halle (Saale) (2014), p. 336.

32. Evely 2000, p. 269-298.

33. Tournavitou 1988, p. 465, fig. 5.

34. On citera la découverte d'un possible axe de rotation d'un tour, d'une rondelle en terre et de ratés de cuisson dans l'habitat de Kontopigado en Attique, qui suggèrent la présence d'un atelier, voir

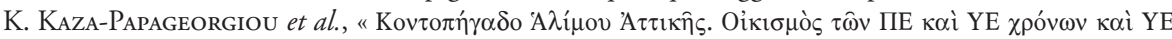

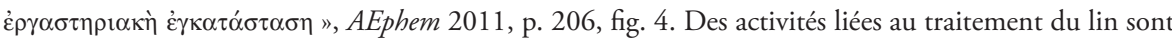
également supposées sur ce site, p. 201-204, fig. 2. 
structure que l'on retrouve toutefois associée à deux reprises à un four de potier, l'une en contexte HR II à Berbati ${ }^{35}$, l'autre en contexte HR III A1-2 à Dimini ${ }^{36}$, est le dépotoir.

Le site de Berbati est intéressant à plusieurs égards. Le four de potier, construit à l'HR II, et le dépôt de rebuts daté de cette phase ont été aménagés dans un espace funéraire plus ancien remontant à la fin de l'HM ${ }^{37}$, qui se trouve sur le côté Sud-Est du Mastos $^{38}$. Le four, dont l'usage se prolonge jusqu'à l'HR II/III A1, peut donc avoir avoir été encore employé lors de l'occupation de la pièce 1 , qui a livré de la céramique de l'HR III A1 incluant quelques exemples à décor figuré ${ }^{39}$. L'essentiel des murs mis au jour dans ce secteur fait toutefois partie d'un bâtiment occupé à l'HR III B et désigné comme étant le Quartier du Potier ${ }^{40}$. Durant cette phase le four de potier était déjà hors d'usage, mais la découverte sur le site de céramique mal faite et trop cuite appartenant à diverses classes céramiques suggère que la production a précédé la construction du four et s'est poursuivie après son abandon : elle s'étendrait de l'HM, en raison de la présence de minyen gris et de céramique à peinture mate, jusqu'à l'HR III B ${ }^{41}$. De plus, Berbati est connu pour avoir été le lieu de production de céramique mycénienne figurée de l'HR III A1 à l'HR III B ${ }^{42}$, un style céramique que l'on retrouve en Argolide et bien au-delà.

Berbati et Tirynthe ne sont vraisemblablement pas les seuls sites à avoir compris un four de potier. Les fouilles menées dans les années 1920 à Asinè ont révélé l'existence de

35. А̊кerström 1987, p. 24-25, fig. 5 (potter's dump).

36. Le four a été mis au jour en bordure est de l'habitat mycénien, dans le terrain Tsakanika, voir V. ADRIMI-

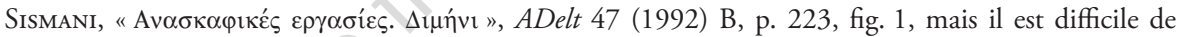

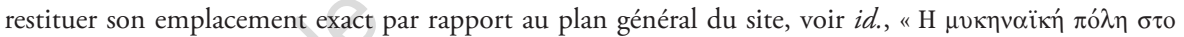

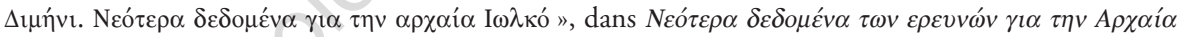
I $\omega \lambda$ кó (1994), p. 21, fig. 1.

37. А̊nerström 1987 , p. 24-25.

38. B. Wells, M. Lindblom (éds), Mastos in the Berbati Valley, Skrifter Utgivna av Svenska Institutet $i$ Athen $4^{\circ}, 54$ (2011), p. 34, fig. 30 .

39. А̊KerSTRÖм 1987, p. 24.

40. Ibid., plan. Les pièces de l'HR III B sont dites bâties au-dessus du four. Une phase de construction plus ancienne peut être associée au four, voir Å. ÅKerströM, En mykensk krukmarkares verstad: frän de svenska utgrävningarna i Grekland åren 1935-1938, dans Arkeologiska forskningar och fynd (1952), summary. Selon le fouilleur, il y aurait là un banc sur lequel reposaient une amphore brisée, une bobine en terre cuite et un fragment de tablette en terre, voir id., "A Mycenaean Potter's Factory at Berbati near Mycenae ", dans Atti e memorie del $1^{\circ}$ congresso internazionale di micenologia. Roma 27 settembre 3 ottobre (1968), p. 49. Pour une lecture critique de la fonction des espaces, voir A.-L. ScHallin, The Late Bronze Age Potter's Workshop at Mastos in the Berbati Valley, dans Gillis et al. 1997, p. 79, plan p. 77, fig. 4.

41. А̊nerström 1987, p. 24.

42. Ibid., p. 24-25. 
deux fours dans l'habitat de l'HR III ${ }^{43}$ dont l'un, dans la pièce XXXIX du bâtiment H, a certainement été destiné à la production céramique en raison du charbon et des tessons mis au jour au Sud-Ouest de la structure ${ }^{44}$. Alors que ces tessons comprenaient, selon toute vraisemblance, différentes classes de céramiques grossières, la présence de céramique fine à décor figuré telle qu'elle a été produite à Berbati n’y est pas signalée par les chercheurs suédois. La production céramique à Asinè se différencie donc de celle de Berbati au sein même de l'Argolide. L'habitat de Berbati fournirait un exemple rare où une classe et un style céramique spécifiques peuvent être associés à un espace de production bien identifié par la découverte d'un four en contexte mycénien.

Malgré l'abondance de céramique mise au jour dans les établissements mycéniens, le lieu et l'espace dans lesquels elle a été produite restent le plus souvent indéterminés. Cette observation concerne par exemple la céramique HR III B entreposée dans les

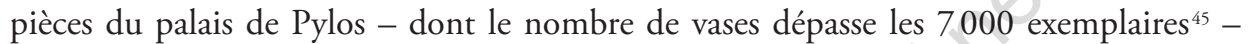
alors que le four de potier mis au jour au Sud-Est du palais appartient à l'horizon HR II de ce site. Le fait que de nombreuses pièces ont servi de magasins palatiaux sera discuté plus loin. Un autre exemple est fourni par les dépôts de Zygouriès, en Corinthie, où plus de 1000 vases inutilisés ont été découverts dans un bâtiment de l'HR III B dénommé magasin de potier (Potter's Shop $)^{46}$. On peut supposer que la céramique a été produite sur le site, comme le proposent certains chercheurs ${ }^{47}$, mais sans pouvoir localiser un espace de production précis au sein de l'habitat ${ }^{48}$.

En revanche, à Mycènes, la possible présence d'un four au Nord-Ouest de la citadelle, suggérée par les résultats d'une prospection magnétique, n’apparaîtrait pas en contexte

43. B. SJöвerg, "Two Possible Late Helladic Kilns at Asine: A Research Note », dans Gillis et al. 1997, p. 89-100; voir C. Davaras, " A Minoan Pottery Kiln at Palaikastro ", BSA 75 (1980), p. 121, n. 23; A. Hansen Streily (n. 4), G2 et G3; Hasaki 2002, p. 109-110. Pour des plans des secteurs, voir O. Frödin, A. Persson, Asine. Results of the Swedish Excavations 1922-1930 (1938), p. 75, 79, fig. 53 , 58. Pour un plan général du site, voir S. DiETz, Asine II. Results of the Excavations East of the Acropolis 1970-1974. Fasc. 1. General Stratigraphical Analysis and Architectural Remains (1982), p. 10, fig. 2.

44. B. SJÖBERG (supra), p. 91.

45. PN I, p. 350. Les vases proviennent en grande majorité de quatre espaces (pantries: rooms 9, 18-22, 60, 67-68), voir T. Whitelaw, « Reading between the Tablets: Assessing Mycenaean Palatial Involvement in Ceramic Production and Consumption ", dans S. Voutsaki, J. Killen (éds), Economy and Politics in the Mycenaean Palace States. Proceedings of a Conference held on 1-3 July 1999 in the Faculty of Classics, Cambridge (2001), p. 52.

46. C. W. Blegen, Zygouries. A Prehistoric Settlement in the Valley of Cleonae (1928), p. 30-38; désignation discutée dans P. M. Thomas, LH IIIB:1 Pottery from Tsoungiza and Zygouries, PhD, University of North Carolina at Chapel Hill (1992), p. 273-274.

47. Par exemple, A. Hansen Streily (n. 4), p. 211 ( Daraus resultierte die Schlußfolgerung, daß die Keramikmagazine Teil einer Töpferwerkstatt seien, die vermutlich in Haus B angesiedelt war »).

48. L'hypothèse qu'il s'agit d'un atelier d'huile parfumée a également été émise, voir P. M. ThомAs (n. 46), p. 274-275, 285-300. 
isolé, puisque la découverte de dépôts d'argile et de ratés de cuisson est également rapportée ${ }^{49}$. On pourrait alors suivre sur le site les étapes d'une production artisanale de son lieu de préparation jusqu'à son lieu de stockage situé à proximité, dans un bâtiment de l'HR III A1 et III A2 qui abritait plus de 500 vases et 150 figurines.

De même, il paraît probable que le four accolé à la Maison de Kadmos ait été impliqué dans la production céramique de Thèbes si l'on tient compte des ratés de cuisson trouvés dans ses débris, d'un dépôt de cendres ainsi que d'argile contenu dans une fosse à proximité ${ }^{50}$. Cette dernière a peut-être servi de fosse de décantation. Le manque de repères chronologiques liés à l'usage du four ne permet pas de déterminer si sa production a pu être contemporaine de l'occupation de la Maison de Kadmos et de l'importation de jarres à étrier durant l'HR III A-B. En outre, ce four a pu être réutilisé pour produire de la chaux ${ }^{51}$.

C'est encore à Thèbes qu'un second four, cette fois-ci utilisé pour le traitement de métaux par chauffe et soudure, a été découvert en contexte artisanal, non pas isolé mais associé à un mobilier spécifique employé dans la production de bijoux et d'appliques. Dans la pièce de l'HR III B1 du terrain A. Kordatzis, qui abritait ce petit four, ont été recueillis des feuilles de plomb, ainsi que des objets finis ou en cours de fabrication, notamment des éléments de parure en or et en lapis-lazuli, ou plus rarement en d'autres matières (cristal de roche, améthyste, agate, verre, stéatite, ambre, coquillages et bronze ${ }^{52}$. Un outil en fer - un foret - et sans doute d'autres outils en bronze et en os y ont aussi été découverts ${ }^{53}$. On peut se demander si de la matière abrasive y a été utilisée et si la meule mise au jour dans ce même espace a servi à des opérations de polissage ou à d'autres fins ${ }^{54}$. Des

49. K. S. Shelton, «A New Linear B Tablet from Petsas House, Mycenae ", Minos 37-38 (2002-2003), p. 387, n. 4 . Cette tablette traite peut-être de la laine, voir ibid., p. 390-392. Dans le cas où on aurait affaire à ce logogramme et non au chiffre 100 , il n'y aurait là pas de lien manifeste entre le sujet de la tablette et la fonction du bâtiment caractérisé par le grand nombre de vases céramiques entreposés. La proposition de lire LANA n'est toutefois pas retenue par S. Iakovidis, L. Godart, A. SACconi, "Les inscriptions en linéaire B découvertes dans la "maison de Petsas" à Mycènes ", Pasiphae 6 (2002), p. 49-50. D’autres fragments ont été mis au jour dans ce bâtiment, voir M. Del Freo, « Rapport 2006-2010 sur les textes en écriture hiéroglyphique crétoise, en linéaire A et en linéaire B ", dans P. CARLIER et al. (éds), Actes du XIII colloque international sur les textes égéens, Sèvres, Paris, Nanterre, 20-23 septembre 2010 (2012), p. 19.

50. A. Dakouri-HiLd, " The House of Kadmos in Mycenaean Thebes Reconsidered: Architecture, Chrono-

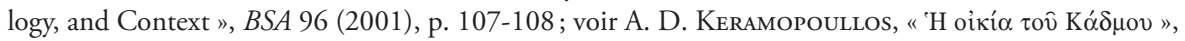

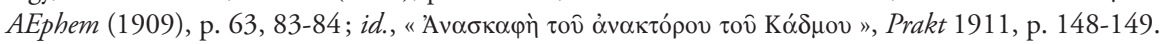

51. Pour cette hypothèse, voir HaSAKI 2002, p. 123.

52. Symeonoglou 1973 , p. 12, 15, 63. Il s'agit de la pièce B.

53. Ibid., p. 15, 70 .

54. Ibid., p. 70; pour la meule, voir aussi p. 15, fig. 23. L'auteur émet l'hypothèse qu’un morceau de stéatite a peut-être servi de matière abrasive, mais cette roche semble plutôt avoir été travaillée qu’utilisée dans ce but. 
éléments de parure et d'appliques ont donc bien été fabriqués et montés dans cette pièce, qui peut être considérée comme un atelier mycénien de bijoutier, comme le propose S. Symeonoglou ${ }^{55}$.

Le même terrain a livré un dépôt important d'ivoires brûlés ${ }^{56}$, qui comprenait aussi quatre perles en or et des restes de bois brûlé. Les objets en ivoire devaient décorer pour la plupart d'entre eux des meubles ou des accessoires. Ils se trouvaient déjà dans un état fragmenté lors de leur combustion, probablement intentionnelle, dans la fosse qui les contenait. L'emplacement exact où les ivoires ont été travaillés avant d'être mis au rebut reste indéterminé. Ce dépôt peut toutefois être associé aux activités du bâtiment $\mathrm{B}-\mathrm{C}^{57}$ et s'intègre en cela dans un contexte artisanal.

Enfin, un dernier exemple peut être mentionné afin de nuancer le caractère isolé qui se dégage des fours artisanaux mis au jour en Grèce mycénienne. Il s'agit de la découverte de scories, de fragments de cuivre et d'un creuset, associée à celle d'un four dans l'habitat mycénien de Volos ${ }^{58}$. Il est difficile de dater le contexte plus précisément au cours de l'Helladique Récent. De plus, on ne sait pas si des objets ont pu y être fabriqués comme à Thèbes ou si seul le métal brut y était traité.

Rares sont les espaces de production métallurgique identifiés par des structures autres que des fours, telles que les foyers de Tirynthe examinés plus haut, ou par la seule présence de résidus tels que des scories trouvées in situ en Grèce mycénienne. Des traces de coulée de métal dans des canaux ainsi que des pièces de cuivre et de métal fondu ont été retrouvées dans l'habitat d'Aidipsos-Koumbi, situé à l'extrémité Nord de l'Eubée, en contexte HR II/III A1 ${ }^{59}$ mais ne peuvent pas être associées à la découverte d'un four artisanal. Encore plus étonnante est l'absence de four de l'âge du Bronze à Thorikos, site du Laurion connu pour ses mines antiques, alors que des

55. Symeonoglou 1973, p. 63-71 (jewelry workshop), voir aussi p. 15. Pour le terme d'orfevre, voir Sampson 1985, p. 28.

56. Symeonoglou 1973 , p. $12,16$.

57. Ibid., p. 17; la preuve de cette association n'est toutefois pas directe en raison du contexte stratigraphique difficile à interpréter, voir ibid., p. 16; la céramique trouvée avec les ivoires date de la fin de l'HR III A2 selon l'auteur, voir ibid., p. 18.

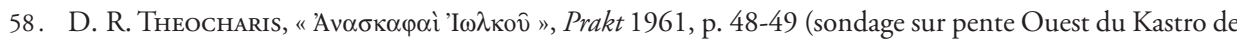

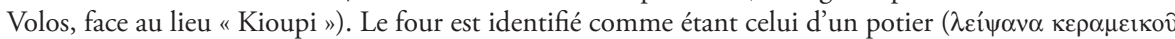
$\kappa \lambda\lrcorner \beta o ́ v o v)$ par le fouilleur mais l'hypothèse d'un four métallurgique est bien plus probable, voir P. Darcque (n. 1), p. 169.

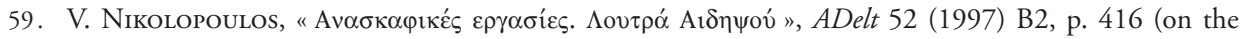

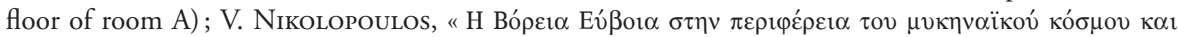

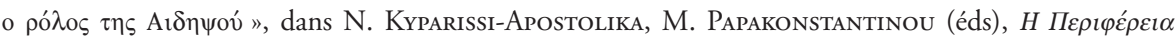

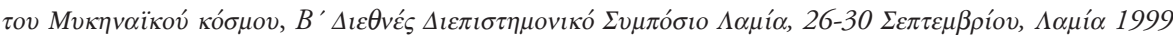
(2003), p. 353, fig. 7. 
pastilles de plomb et des morceaux de litharge ont été mis au jour sur le sol d'un bâtiment occupé de la fin de l'Helladique Moyen à l'HR I ${ }^{60}$.

\section{DÉPÔTS D’OUTILS ET D’OBJETS SEMI-FINIS}

\section{i. 1. Ateliers ou magasins}

Le dépôt d'outils, de matière première et d'objets partiellement travaillés dans une même pièce sert en règle générale d'argument majeur pour reconnaître l'existence d'un atelier. C'est principalement leur découverte conjointe dans un même espace qui permet d'éviter un usage abusif de ce terme ${ }^{61}$.

Les difficultés liées à l'identification d'ateliers ont été le plus clairement discutées pour les exemples de Mycènes. Elles concernent les dépôts d'ivoire mis au jour dans la Maison des Boucliers et la Maison des Sphinx ${ }^{62}$, situées au Sud-Ouest de l'acropole. Le matériel trouvé dispersé dans les nombreuses pièces de ces bâtiments de l'HR III B1 est sans doute tombé d'un étage. Il se compose essentiellement de pièces d'ivoire presque finies, qui auraient pu être laissées là en attente, avant d'être acheminées ailleurs. Néanmoins, ces ivoires semblent avoir été montés dans ces deux maisons sur des supports de matière périssable, en raison du nombre important de restes de bois carbonisés mis au jour ${ }^{63}$.

Les outils découverts dans ces bâtiments paraissent toutefois peu nombreux. Il s'agit d'outils en pierre recueillis dans la Maison des Sphinx ainsi que d'outils en bronze, c'està-dire deux couteaux et une scie, trouvés dans la Maison des Boucliers ${ }^{64}$. Les autres objets en métal mis au jour dans ce dernier bâtiment ne sont pas des outils, mais une pointe de lance et des ornements personnels ${ }^{65}$. Parmi les outils en pierre de la Maison des Sphinx, cinq d'entre eux sont des outils de mouture; une meule, qui a peut-être servi à réduire en

60. J. Servais, «Les fouilles sur le haut du Vélatouri », dans H. F. Mussche et al. (éds), Thorikos 1965. Rapport préliminaire sur la troisième campagne de fouilles (1967), p. 22, fig. 16.

61. Pour une mise en garde, voir Sampson 1985, p. 28; Quartier Mu III, p. 1; O. H. Krzyszkowska, "Cult and Craft: Ivories from the Citadel House Area, Mycenae ", dans Laffineur, Betancourt 1997, p. 145.

62. Tournavitou 1995; P. Darcque, "Mycènes : une ville ou un palais?", dans I. Bradfer-Burdet,

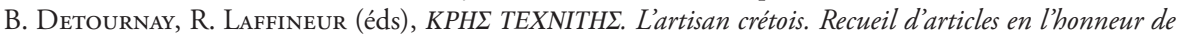
Jean-Claude Poursat, publié à l'occasion des 40 ans de la découverte du Quartier Mu, Aegaeum 26 (2005), p. 51-60.

63. Tournavitou 1995 , p. 193 : «the ivories were delivered here in a practically finished state and were then fitted onto various pieces of furniture, probably wooden ".

64. Tournavitou 1997, p. 246.

65. Ibid., p. 247. 
poudre de la pierre ponce, pourrait se rapporter à des activités artisanales ${ }^{66}$. En outre, on notera la découverte de quelques pièces d'ivoire, d'outils - dont un moule en pierre - et de lames d'obsidienne dans la Maison du Marchand d'huile ${ }^{67}$, ce qui renforce le cadre artisanal de la zone examinée. Ce bâtiment voisin des deux précédents est toutefois principalement connu pour avoir abrité de nombreuses jarres à étrier ${ }^{68}$, dont la présence indique clairement un espace de stockage.

La découverte d'obsidienne dans la Maison des Boucliers et la Maison des Sphinx, au nombre de 24 exemplaires dans la première et de 27 dans la seconde ${ }^{69}$, peut également servir d'argument en faveur du travail de l'ivoire. Il s'agit principalement de lames et d'éclats qui, une fois emmanchés, pourraient être considérés comme des restes d'outils à part entière ${ }^{70}$. Un tel usage augmente nettement le nombre potentiel d'outils susceptibles d'être utilisés dans le travail de finition de l'ivoire, mais ces lames et éclats pourraient également avoir été gardés là en attente d'être emmanchés ailleurs. En comparaison, les lames d'obsidienne sont rares, seulement au nombre de trois, dans la Maison des Artisans, située sur l'acropole, alors que le travail de l'ivoire y est attesté par la présence abondante de pièces d'ivoire non finies, ainsi que de deux outils en métal et de la matière brute collante $^{71}$. Ce bâtiment a été détruit par un incendie à la transition entre l'HR III B2 et l'HR III C ancien, c'est-à-dire près de cent ans après les bâtiments situés au Sud-Ouest de l'acropole.

C'est sur la base du mobilier de la Maison des Artisans qu'un critère de distinction essentiel supplémentaire a été proposé par I. Tournavitou pour différencier les ateliers des magasins. Il repose sur le pourcentage d'objets inachevés face à celui d'objets finis. Dans ce bâtiment, $50 \%$ des ivoires, dont le total s'élève à 1586 exemplaires, sont des pièces semi-finies ou inachevées ${ }^{72}$. En comparaison, le pourcentage d'ivoire partiellement

66. Tournavitou 1995, p. 232.

67. Ibid., p. 28-41, 227, 233 (pierre), 254 (obsidienne).

68. Ibid., p. 31-32, 71 .

69. Ibid., p. 253-254.

70. Pour des exemples d'outils crétois, voir R. D. G. Evely, Minoan Crafts: Tools and Techniques. An Introduction, SIMA 92/1 (1993), p. 128-134, fig. 58-60. Selon Tournavitou 1995, p. 254, les éclats provenant de la Maison des Boucliers ne peuvent toutefois pas être interprétés comme des outils dans ce contexte, contrairement aux lames découvertes dans les deux maisons.

71. Il s'agit d'un crochet en métal, d'un ciseau en bronze, de restes de peinture bleue et d'une substance jaune collante, voir Tournavitou 1997, p. 237; voir aussi Tournavitou 1995, p. 192.

72. Tournavitou 1997, p. 237. Pour le plan du bâtiment et un comptage préliminaire du matériel en ivoire, voir G. E. Mylonas, "The East Wing of the Palace of Mycenae ", Hesperia 35 (1966), p. 425 (778 pièces). Le même critère de distinction est proposé par l'auteur pour les ivoires mycéniens de Délos, voir I. Tournavitou, "The Mycenaean Ivories from the Artemision at Delos », BCH 119 (1995), p. 527 : "A local workshop on Delos with Mainland or Mainland trained craftsmen would be quite plausible, especially considering the albeit small percentage of partly worked/unfinished items ». 
travaillé estimé pour la Maison des Boucliers et la Maison des Sphinx, qui s'élève à 1,6 \%, est négligeable. L'auteur voit là des traces d'activités artisanales qu'elle considère, à juste titre, comme secondaires ${ }^{73}$. Ces deux derniers bâtiments semblent avoir abrité des ateliers de montage plutôt que de fabrication, contrairement au " centre cultuel ", où a été gardé de l'ivoire, peut-être des pièces mises au rebut, mais où le reste du mobilier ne suggère ni la présence d'un atelier de montage ni d'un atelier de fabrication ${ }^{74}$.

Le site mycénien de Thèbes mérite à nouveau une attention particulière (fig. 4). Outre l'atelier du terrain A. Kordatzis examiné ci-dessus, trois autres espaces mis au jour sur la Cadmée sont susceptibles d'avoir abrité des activités artisanales en contexte HR III B1. On revient ici sur les raisons qui ont mené à les identifier, en général, comme ateliers ${ }^{75}$. Il s'agit tout d'abord d'une pièce mise au jour dans le terrain Koropoulis, qui a livré des bijoux en pierre précieuse, des pièces en cristal de roche travaillées et non travaillées, ainsi que des outils en pierre et en bronze, notamment un moule en pierre destiné à la production d'anneaux en métal, et d'autres objets ${ }^{76}$. La découverte de feuilles de plomb est aussi rapportée. Cependant, ni ces feuilles ni le moule ne peuvent être mis en relation avec une structure de combustion, tel un four. De plus, l'hétérogénéité du mobilier - qui comprend également des pointes de flèche en bronze et une large main en terre cuite appartenant à une statuette - fait davantage penser à du matériel entreposé que fabriqué ou produit à cet endroit. Malgré cela, le contexte artisanal, dû à la présence d'outils et d'objets semi-finis, semble prévaloir sur ce terrain qui n'est encore que partiellement fouillé, et l'existence d'un atelier, comme le soutient K. Demakopoulou, paraît tout à fait vraisemblable ${ }^{77}$.

On notera également la découverte, à Dimini, de mobilier semblable, qui compte du plomb, un moule et des outils en pierre, dans un espace identifié comme atelier ${ }^{78}$. Cet espace pourrait avoir été en relation directe avec le four mis au jour en limite Est de l'habitat mycénien mentionné plus haut ${ }^{79}$.

73. Tournavitou 1995 , p. 193 (" some sort of workshop activity »), p. 213 (" secondary workshop activities ").

74. Cet avis est soutenu par Poursat 1977, p. 135; O. H. Krzyszkowska (n. 61), p. 148; P. Darcque (n. 62), p. 57.

75. A. Dakouri-Hild, "Making La Différence: The Production and Consumption of Ornaments in Late Bronze Age Boeotia ", dans M.-L. Nosch, R. Laffineur (éds), KOSMOS. Jewellery, Adornment and Textiles in the Aegean Bronze Age. Proceedings of the 13th International Aegean Conference, 21-26 April 2010 (2012), p. 472 (the Kordatzi 'hoard' and workshop, the Tzortzi workshop, the Koropouli workshop, the Loukou workshop).

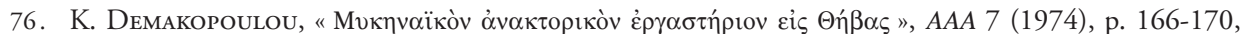

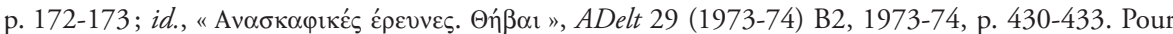
les moules, et plus particulièrement ceux de Thèbes, voir Tournavitou 1997, p. 213, 222, 232, 239.

77. K. Demakopoulou (supra). Voir aussi Tournavitou 1988, p. 466 ; Demakopoulou 2014, p. 144.

78. C'est en tout cas l'identification qu'en fait V. Adrimi-Sismani (n. 36, 1994), p. 27 (atelier, terrain Zoographou).

79. V. Adrimi-Sismani (n. 36, 1992), p. 223, fig. 1 (terrain Tsakanika). 
De retour à Thèbes, on signalera un autre espace d'activités artisanales possible sur la Cadmée à l'HR III B1, identifié comme atelier par K. Demakopoulou ${ }^{80}$. Des fragments d'ivoire semi-finis ou non travaillés, de l'or, ainsi que des outils en pierre, en os et en bronze, comme des ciseaux et des fragments de couteaux, ont notamment été recueillis dans l'espace bâti du terrain des frères Tzortzis ${ }^{81}$. Là encore, d'autres objets ont pu être entreposés tels que des feuilles en or abîmées et peut-être des fragments de peinture murale qui semblent avoir été mis au rebut. Comme dans le terrain Koropoulis, la découverte de matériel semi-fini et d'outils fait toutefois pencher en faveur de la présence d'un atelier plutôt que d'un simple espace de stockage.

Enfin, l'existence d'un atelier à l'HR III B1 dans le terrain M. Loukos est identifiée par A. Sampson ${ }^{82}$. Cette interprétation repose là aussi essentiellement sur la découverte d'ivoire dont la plupart des fragments trouvés dans la pièce 1 de ce terrain étaient en cours de fabrication ${ }^{83}$. Ils devaient provenir d'un étage et être gardés près d'un mur sur une étagère. Des poids ont peut-être servi à peser ce matériau. En l'absence d'outils, il pourrait aussi s'agir d'un matériel entreposé au premier étage de cette pièce en attente d'être fini et monté là ou ailleurs sur la Cadmée.

Les dépôts d'objets semi-finis et de matériel brut sont les plus difficiles à interpréter en termes d'activités artisanales menées in situ. En ce qui concerne les pièces de la Maison de Kadmos, voisines du four artisanal, qui ont livré du mobilier en pierres précieuses ou en or, je rejoindrai l'avis d'A. Dakouri-Hild sur le fait que le matériel d'un atelier a pu être entreposé dans cette partie du bâtiment ${ }^{84}$. Bien que le matériel étudié représente diverses étapes de production, on ne peut pas confirmer qu'il ait été travaillé dans les pièces mêmes.

80. Demakopoulou 2014, p. 146.

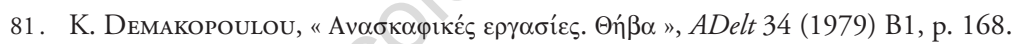

82. Sampson 1985 , p. 28 . Tout en soutenant l'existence d'un atelier, l'auteur suggère que la pièce $1 \mathrm{a}$ pu servir à des activités artisanales ou commerciales, notamment en raison de poids de pierre. En faveur

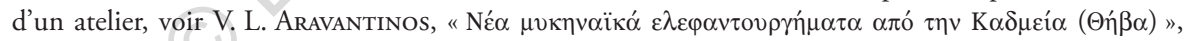

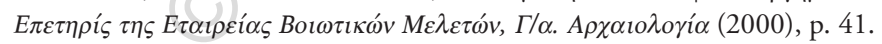

83. Sampson 1985 , p. 25 et 28 . Le dépôt mis au jour sur le sol de la pièce 1 comprend des centaines de fragments d'ivoire, deux peignes en ivoire, huit poids en pierre, cinq boutons et des fusaïoles en stéatite, et des vases. Identification admise par Demakopoulou 2014, p. 146.

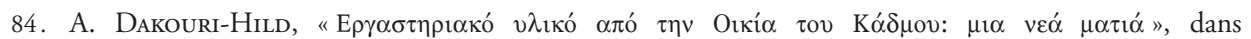

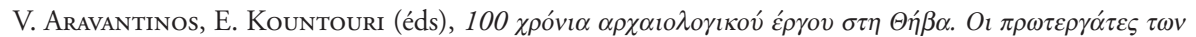

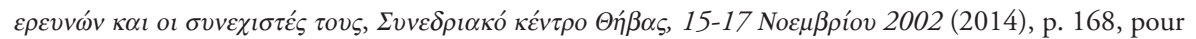
la répartition du mobilier en pierre, voir fig. 6 à p. 166. La présence d'un atelier est évoquée dans Symeonoglou 1973, p. 91, n. 401 (fils d'or); K. Demakopoulou (n. 76, 1974), p. 162; voir aussi Demakopoulou 2014, p. 143. Pour la pièce $\Xi$, voir A. D. Keramopoullos (n. 50), p. 147 (perles

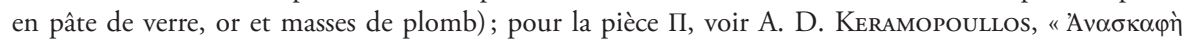
Onß⿵人v ", Prakt 1927, p. $42-43$ (3 objets en or); voir S. Symeonoglou, The Topography of Thebes from the Bronze Age to Modern Times (1985), p. 220 (pièce $\Xi), 221$ (pièce П). 
Enfin, la découverte d'outils dans le terrain D. Liagas, notamment celle d'un moule en pierre orné d'une rosette et de trois pierres à aiguiser ainsi que d'un couteau en bronze, dans chacune des deux pièces d'un bâtiment détruit à l'HR III B2 suggère que des activités artisanales ont pu être menées à cet endroit ou à proximité ${ }^{85}$ à une phase postérieure de 50 à 100 ans à celles de l'HR III B1, non plus au centre de la Cadmée mais sur son côté oriental. Ces pièces ont toutefois compris des outils de fonction diverse, notamment des outils de mouture, qui n'ont pas été utilisés dans un cadre artisanal. La fonction du bâtiment était sans doute polyvalente puisque les broyeurs et meules en pierre mis au jour dans l'une des pièces, ainsi que des restes végétaux - à savoir des graines brûlées découverts dans l'autre pièce s'intègrent bien mieux à un espace domestique. La présence d'une double hache en bronze dans la pièce qui a livré sept petits disques en ivoire et les graines s'explique en outre difficilement. L'ivoire ne semble pas avoir été travaillé dans cet espace mais devait décorer meubles ou objets. Non loin, à l'Ouest du terrain Liagas, dans la partie Sud-Est de la Cadmée (terrain Kofini), un autre complexe bâti a livré de l'ivoire dont seule l'étude nous permettra de nous prononcer davantage sur le contexte, mais l'existence d'activités liées à l'industrie textile à l'HR III B2, dont il sera question plus loin, est déjà supposée ${ }^{86}$.

Durant la même phase, un bâtiment situé dans la partie Nord de la Cadmée pourrait avoir abrité des activités artisanales ${ }^{87}$, en raison des dents de sanglier mises au jour dans une pièce et des objets en ivoire dans une autre ainsi que d'un fragment de pierre ponce qui aurait pu servir à les lisser. Il est toutefois difficile de confirmer que le matériel entreposé là aurait pu être travaillé sur place sans la présence d'autres outils.

Outre les exemples de Mycènes et de Thèbes, il convient de se pencher sur les découvertes de deux autres sites, Tirynthe et Midéa. À Tirynthe, d'une part, l'ivoire mis au jour provient de différents niveaux de la citadelle ${ }^{88}$. Les exemplaires dont le contexte est connu, qu'il s'agisse d'objets finis, semi-finis ou de fragments, ont été retrouvés éparpillés dans les différents espaces et ne constituent pas de dépôts majeurs qui marqueraient une aire de stockage ou de travail.

À Midéa, d'autre part, un moule, des outils en pierre, bronze et os ainsi que des pierres semi-précieuses visiblement non travaillées font partie du mobilier recueilli dans un

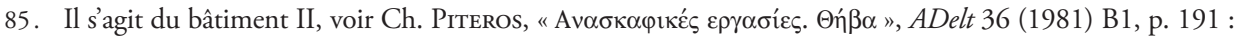
pièce $\Gamma$, côté Est : tessons, fragment de moule en pierre, 3 pierres à aiguiser brûlées, broyeurs et meules en pierre; pièce $\Delta$ : tessons, 18 boutons en stéatite, double hache en bronze, couteau en bronze, 7 disques en ivoire brûlés, graines brûlées, jarre à étrier. Pour la présence d'un atelier, voir Demakopoulou 2014, p. 150.

86. Alberti et al. 2012, p. 89.

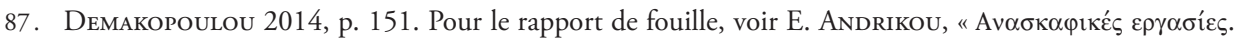

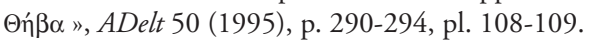

88. O. H. KrzyszKowska, « Mycenaean Ivories from Tiryns », Tiryns XIII (2005), p. 179-213. 
complexe bâti près du mur de fortification et daté de la fin du XIII ${ }^{\mathrm{e}} .^{89}$. On ne connaît pas la répartition spatiale du mobilier ni son état de finition. Le matériel a pu être travaillé là ou seulement entreposé, comme d'autres objets, notamment des modèles et appliques en ivoire ${ }^{90}$. De plus, la découverte de matériaux bruts, de pierres semi-précieuses et d'outils dans un secteur bâti situé plus au Nord laisse supposer l'existence d'un autre espace d'activités artisanales intégré, toutefois, dans une aire à fonction polyvalente, puisque figurines et statuettes en terre cuite, vases en pierre et métal, bijoux et sceaux y ont été mis au jour ${ }^{91}$.

En revanche, le matériel publié du palais de Pylos permet d'avancer quelques hypothèses. L'ivoire découvert dans le palais de l'HR III B2 - principalement dans les pièces 23 et 24,30 à 33 , et le corridor $25^{92}$ - semble être du matériel mis au rebut, vraisemblablement tombé de l'étage. En effet, l'ivoire a été découvert dans un état fragmenté, cassé et, dans le cas de la pièce 33, brûlé et endommagé. Il est difficile d'affirmer que ce mobilier devait être retravaillé dans une des salles du palais et, pour cette raison, il serait sans doute préférable de considérer les pièces qui se trouvaient à l'étage comme lieux d'entreposage plutôt que comme espaces de production artisanale. On ne peut toutefois pas totalement exclure que de telles activités aient été accomplies au-dessus de la pièce 30 qui comprenait de l'ivoire dépourvu de décor.

De même, on peut se demander si le Bâtiment Nord-Est de Pylos doit être considéré comme un atelier; il est désigné comme tel par C. Blegen, mais reconsidéré comme un complexe bâti consacré au stockage par L. M. Bendall ${ }^{93}$. Le mobilier y était varié, et comprenait de rares outils ${ }^{94}$. Certains éléments ont pu intervenir à un moment donné du processus de fabrication d'objets, tels les fils et les rivets de métal, ou étaient prêts à être montés sur un support périssable, comme des perles en matières diverses, des pointes de flèches en bronze ou des fragments d'ivoire. Toutefois, de nombreux objets, comme des vases céramiques, étaient finis. Ces éléments pourraient indiquer la présence d'un atelier de montage, notamment en ce qui concerne la pièce 100 où le mobilier principalement

89. K. Demakopoulou, The Mycenaean Acropolis of Midea (2012), p. 26 (zone 3), p. 30, fig. 37 (cristal de roche), fig. 38 (moule en stéatite); voir aussi Tournavitou 1997, p. 213, moule no 19.

90. Le mobilier inclut aussi de la vaisselle en pierre et en plomb, des figurines en terre cuite, un miroir et des perles en verre. Voir aussi A.-L. Schallin, "Mycenaean Jewellery and Adornment at Midea", dans M.-L. Nosch, R. Laffineur (n. 75), p. 512; voir les rapports de fouilles dans OpAth 19 (1992), p. 11-15; OpAth 21 (1996), p. 13-24; OpAth 22-23 (1997-1998), p. 57-73.

91. K. Demakopoulou (n. 89), p. 22.

92. PNI, p. 134-144, et 151-163.

93. Ibid., p. 299-325; L. M. BendalL, "A Reconsideration of the Northeastern Building at Pylos: Evidence for a Mycenaean Redistributive Center ", AJA 107 (2003), p. 181-231.

94. Il s'agit principalement de ciseaux, voir L. M. Bendall (supra), p. 189, 193, fig. 5, mais la présence de lames dans le Bâtiment Nord-Est est écartée par l’auteur, voir p. 189. 
constitué de pointes de flèches comprend également des fragments d'ivoire ${ }^{95}$. La diversité du mobilier réparti dans le reste du bâtiment ainsi que la présence de scellés et de tablettes en argile font cependant davantage penser à un magasin qu'à un atelier ${ }^{96}$.

L'obsidienne et le silex recueillis dans les différentes pièces du palais de Pylos se composent principalement d'éclats, de chutes et de débris. Bien que les éclats puissent servir de burins ${ }^{97}$, on soulignera la rareté des lames, réparties dans trois espaces différents ${ }^{98}$, qui, emmanchées, pourraient avoir servi de couteaux et de poinçons. Du silex et de l'obsidienne ont également été trouvés dans la cour 47 du palais, espace susceptible d'avoir été l'endroit où a été produite de l'huile parfumée à Pylos ${ }^{99}$, mais dépourvu de structures destinées à la chauffe d'onguents. Seules de telles structures pourraient confirmer l'usage de cet espace comme atelier plutôt que comme réserve. En outre, on doit écarter l'hypothèse d'une aire de débitage lithique en raison de la rareté des nucléus provenant de ces pièces ${ }^{100}$.

Enfin, on notera le manque d'outils en pierre polie, en bronze ou en os, aussi bien dans les pièces susmentionnées du palais de Pylos que dans le Bâtiment Nord-Est, hormis la découverte d'une pierre à aiguiser fragmentée provenant de la pièce 97 de ce dernier bâtiment ${ }^{101}$. L'absence d'outils dans la pièce 55 du palais nous fait également hésiter à considérer cet espace comme un atelier de sculpteur sur pierre malgré la présence de sept blocs de poros, d'un élément cylindrique et d'une lampe non finie ${ }^{102}$, laissant supposer que ce mobilier a pu être entreposé là dans l'attente d'être travaillé ailleurs.

\section{2. Travail De L'ivoire et CADre Palatial}

Ce sont dans des sites palatiaux (Mycènes, Thèbes et Pylos), en contexte HR III B, que d'abondantes masses de pièces en ivoire semi-finies ou cassées ont été entreposées (fig. I); elles étaient destinées à être travaillées sur place dans certains cas. En outre, le site fortifié

95. PN I, p. 325; voir aussi Poursat 1977, p. 137.

96. Pour la répartition des scellés à Pylos et leur rôle dans la réception de biens, voir L. M. Bendall (n. 93), p. 202-203, fig. 14, pour les documents en linéaire B, voir p. 201, fig. 12 et 13.

97. Pour la Crète, voir R. D. G. Evely (n. 70), p. 150-151, fig. 64.

98. PN I, p. 144 (corridor 25), 155 (pièce 31), 163 (pièce 33).

99. Pour l'identification d'un atelier, voir C. W. Shelmerdine, The Perfume Industry of Mycenaean Pylos (1985), p. 61-62. Identification suivie par Tournavitou 1988, p. 448, 456, fig. 2. Pour la cour 47 et son mobilier, voir PNI, p. 203-209.

100. Pour de rares nucléus d'obsidienne, voir PN I, p. 303 (pièce 92), 311 (pièce 97). La même observation vaut pour la pointe Nord de la citadelle basse de Tirynthe qui a livré plusieurs éclats d'obsidienne, voir Brysbaert, VetTers 2013, p. 194, table 6.

101. PNI, p. 311.

102. Selon Poursat 1977 (p. 137), il s'agit d'un véritable atelier de sculpteur sur pierre. La présence d'un atelier est également supposée par Tournavitou 1988, p. 448. 
de Midéa, où ont été mis au jour pierres semi-précieuses et ivoire, fait sans aucun doute partie du système palatial qui prédomine en Grèce mycénienne au cours de cette phase. Le fait que ce matériau soit importé lui ajoute une valeur certaine ${ }^{103}$. L'ivoire découvert en contexte plus ancien appartient essentiellement à du mobilier funéraire ${ }^{104}$.

Dans le cas de Thèbes, fours et dépôts d'ivoire et de matières précieuses se répartissent sur différents terrains fouillés sur la Cadmée, à faible distance les uns des autres $^{105}$ (maximum $70 \mathrm{~m}$ ). Si l'on ajoute à ces espaces ceux qui ont été reconnus pour avoir abrité des objets précieux - telle la Salle du Trésor - des armes en bronze et des éléments d'harnachement en ivoire - telle l'Hoplothèque ${ }^{106}$ - on s'aperçoit que les lieux d'entreposage et les espaces de production artisanale pourraient couvrir une bonne partie du centre et centre-Sud de la Cadmée ${ }^{107}$. Dans cette partie de l'agglomération, les vestiges de l'HR III B semblent être essentiellement de nature palatiale, en raison de leur abondance, de leur richesse et de leur valeur décorative, comme l'atteste la découverte de peintures murales ${ }^{108}$, ou de par leur valeur administrative, comme en témoignent les tablettes et nodules en linéaire $\mathrm{B}^{109}$.

En ce qui concerne l'ivoire (e-re-pa), les documents en linéaire B de Cnossos et de Pylos nous apprennent que ce matériau ornait des chars et du mobilier ${ }^{110}$. On rappellera que la majorité des tablettes, notamment celles de la série Ta où il est mention d'ivoire, proviennent des pièces du palais nommées Archives Room ${ }^{111}$. Les pièces du palais qui

103. Brysbaert, Vetters 2013, p. 179-180.

104. Poursat 1977, p. 11-14. Les dépôts secondaires comprenant de l'ivoire sont également recensés.

105. Pour cette faible distance et leur lien avec le palais mycénien, voir SAmpson 1985, p. 28.

106. V. L. Aravantinos (n. 82), p. 42, catalogue, p. 52-73.

107. Pour un plan du centre et centre-sud de la Cadmée, voir A. Dakouri-Hild (n. 50), p. 102, fig. 11. Pour la

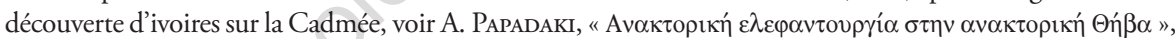

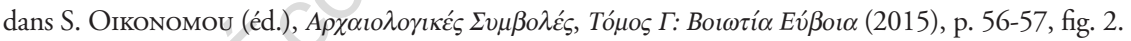

108. Par exemple les maisons du terrain Antoniou, qui ne correspondent toutefois pas à des espaces de stockage ou de production artisanale, voir A. DaKouri-Hild (n. 50), p. 103.

109. V. L. Aravantinos, L. Godart, A. Sacconi, Thèbes. Fouilles de la Cadmée I. Les tablettes en linéaire B de la Odos Pelopidou. Édition et commentaire (2001).

110. Poursat 1977, p. 257, pour de l'ivoire brut, voir p. 261. DMIC 1, s.v. «e-re-pa» et dérivés (KN Ce 144, Og 7504, Ra 1028, Sd 4401, Sd 4403, Sd 4408, Sd 4412, Se 891, Se 1007, V 684, Va 482, Vc 212, X 8107 et probablement X 7814; PY Ta 642, Ta 707, Ta 708, Ta 713, Ta 715, Ta 721, Ta 722). E. R. Luján, A. Bernabé, "Ivory and Horn Production in Mycenaean Texts ", dans M.-L. Nosch, R. LAfFineur (n. 75), p. 627-637, pour la série cnossienne et le travail de l'ivoire, voir p. 635.

111. PTT, p. 231-232 (Annex Room 7). Ces tablettes livrent des inventaires de vaisselles et de meubles, voir Documents ${ }^{2}$, p. 332-348; C. W. Shelmerdine, "Mycenaean Furniture and Vessels: Text and Image", dans M.-L. Nosch, R. Laffineur (n. 75), p. 685-695. La traduction de e-re-pa-te-ja comme « incrusté d'ivoire " correspondrait au matériel trouvé à Pylos, voir A. BernabÉ, E. R. LuJÁN, « Mycenaean Technology ", dans Y. Duhoux, A. Morpurgo Davies (éds), A Companion to Linear B. Mycenaean Greek Texts and their World, vol. 1 (2008), p. 202. 
ont livré une masse abondante d'ivoire abritaient également des tablettes ${ }^{112}$, mais aucune d'elles ne fait allusion à ce matériau ${ }^{113}$. Les tablettes mises au jour dans le Bâtiment NordEst ne font pas non plus mention d'ivoire et, de plus, ne proviennent pas de la pièce 100 qui a livré l'essentiel de ce matériau mais de la pièce $99^{114}$.

Les documents en linéaire $\mathrm{B}$ découverts dans le quartier Sud-Ouest où se trouvent la Maison des Boucliers et la Maison des Sphinx, qui ont toutes deux livré un nombre important d'ivoires, ne mentionnent pas ce matériau, mais concernent cinq sujets différents : l'huile, la laine, le personnel, les épices et les rations ${ }^{115}$. Sur deux des tablettes découvertes dans la Maison du Marchand d'huile apparaissent des quantités de laine, entre autres destinées à un potier et à un forgeron ${ }^{116}$, mais ce bâtiment n'abritait manifestement pas d'activités artisanales liées à ces types de productions. C'est également de ce bâtiment que provient une tablette portant la mention de dix-sept boulangers (MY Au 102) ${ }^{117}$, mais aucun four ne suggère que des aliments ont été cuits là. En revanche, le bâtiment devait centraliser des informations de diverse nature à l'HR III B1.

Le fait que ces bâtiments forment une sorte de quartier distinct du palais édifié au sommet d'une acropole fortifiée conduit I. Tournavitou à s'interroger sur l'existence d'un secteur " privé », presque indépendant du palais, à l'image de ce que rapportent les sources du Proche-Orient ${ }^{118}$. L'auteur ne rejette pas l'hypothèse d'opérations privées, mais souligne le fait que celles-ci devaient être liées au contrôle du palais ${ }^{119}$. L'éloignement topo-

112. PN I, p. 137 (pièce 23 : tablettes nos 1215-1246, 1249), 141 (pièce 24 : étiquette no 1247), 159 (pièce 32 : tablettes nos $1194,1198,1200$; étiquette no 1199 ).

113. Tablettes de la série Fr trouvées dans les pièces $23,24,32,38,41,43$, la cour 63, les pièces 71-72, et 103, voir PTT, p. 159. Elles concernent des offrandes d'huile (idéogramme* 130 OLE), voir Documents ${ }^{2}$, p. 476-483.

114. Pièce 99: An 1281 et 1282, série Ub, Un 1314-1322; Va 1323-1324, Vn 1339[+]1456, voir PTT, p. $57,240,248,252,257$.

115. Trois maisons du quartier Sud-Ouest ont livré la grande majorité des tablettes (la Maison Ouest, la Maison du Marchand d'huile et la Maison des Sphinx), voir Tournavitou 1995, p. 257-269, sp. 258; pour les tablettes de Mycènes, voir aussi J. L. Melena, J.-P. Olivier, TITHEMY. The tablets and Nodules in Linear B from Tiryns, Thebes and Mycenae, Suplementos a Minos 12 (1991), p. 20-23, 53-76.

116. Pour ke-ra-me-wi[ (MY Oe 125), pour ka-ke-wi (MY Oe 121), au datif singulier, voir DMIC 1; J. L. Melena, J.-P. Olivier (supra), p. 21, 66-67. Pour la série Oe de tablettes de Mycènes avec l'idéogramme LANA, voir Documents², p. 322-323; C. VARIAs GARCÍA, «Algunas consideraciones en torno a las tablillas textiles (serie Oe) de Micenas ", dans Actas del VIII Congreso Español de Estudios Clásicos I, Madrid, 23-28 de septiembre de 1991 (1994), p. 315-322. Pour la tablette de la Maison Petsas susceptible de traiter de la laine, voir plus haut, n. 49.

117. Documents², p. 179; J. L. Melena, J.-P. Olivier (n. 115), p. 20, 53.

118. Tournavitou 1995, p. 297. On notera qu'un secteur "privé " peut comprendre des activités d'une ampleur qui dépasse le cadre domestique. En ce qui concerne Mycènes, M. Ventris et J. Chadwick remarquent déjà que 17 boulangers semblent être un nombre élevé pour figurer sur une tablette provenant d'une maison privée (Documents' ${ }^{2}$ p. 179).

119. Tournavitou 1995, p. 298. 
graphique entre ce quartier et le palais à Mycènes attire également l'attention de P. Darcque, qui ne conçoit pas la distance comme un critère d'indépendance vis-à-vis du palais mais voit dans les bâtiments du quartier Sud-Ouest le siège où l'élite mycénienne installe une partie de ses activités administratives et artisanales ${ }^{120}$. L'auteur explique en termes de «ville-palais » l'emprise du palais dans des zones situées hors de la citadelle. Quel que soit le degré d'indépendance du quartier Sud-Ouest de Mycènes, les activités de ses occupants ne pouvaient guère, à mon avis, échapper à l'œil du palais qui les surplombait.

\section{ORGANISATION SPATIALE DES PRODUCTIONS ARTISANALES ET DIVERSITÉS GÉOGRAPHIQUES ${ }^{121}$}

\section{1. NOMS DE MÉTIER ET TOPONYMES}

L'organisation des productions artisanales et de la société dans le monde mycénien est un thème de recherche qui recouvre autant le domaine de l'archéologie que celui de la mycénologie. Les documents écrits mycéniens, en particulier ceux de Pylos, nous renseignent sur les productions artisanales, tout d'abord par l'existence de noms de métier comprenant des artisans et des ouvriers agricoles ${ }^{122}$ : entre autres, celui de potier $(k e-r a-m e-u)$ et ses dérivés mentionnés sur des tablettes de Pylos ${ }^{123}$, celui de forgeron

120. P. DARCQue (n. 62), p. 58-59. L'auteur parle de transformation de l'ivoire.

121. L'expression « diversités géographiques » est employée dans Poursat 1977 (p. 141) dans un chapitre qui se concentre toutefois sur l'origine du mobilier ou la part d'influence étrangère que celui-ci comprend.

122. Documents ${ }^{2}$, p. 123. Parmi les noms de métier cités dans Documents ${ }^{2}$ se trouvent ceux de la construction : maçons (to-ko-do-mo), charpentiers (te-ko-to); constructeurs de navires (na-u-do-mo); travailleurs de métaux : forgerons $(k a-k e-u)$, couteliers? (pi-ri-je [étymologie : verbe "scier "]); autres manufactures : fabricants d'arcs (to-ko-so-wo-ko), de chaises? (to-ro-no-wo-ko), potiers (ke-ra-me-we); fabricants de tissu : cardeurs, fileurs, tisseurs (féminin : pe-ki-ti-ra $, a-r a-k a-t e-j a, i-t e-j a-o$ ), travailleur de lin (ri-ne$j a)$, foulon (ka-na-pe-u); métiers du luxe: occupés à la chauffe d'onguents (a-re-pa-zo-o), orfèvres ( $k u$-ru-so-wo-ko). Il y a aussi la mention de boulangers (a-to-po-qo: artopoquoi), voir Documents ${ }^{2}$, p. 179 (MY Au 102). Voir aussi A. Morpurgo Davies, "Terminology of Power and Terminology of Work in Greek and Linear B ", dans E. Risch, H. Mühlestein (éds), Colloquium Mycenaeum, Actes du sixième colloque international sur les textes mycéniens et égéens tenu à Chaumont sur Neuchâtel du 7 au 14 septembre 1975 (1979), p. 99-103, pour pi-ri-je-te-re, p. 105. Voir aussi P. CARLIER, "À propos des artisans wa-naka-te-ro ", dans E. De Miro, L. Godart, A. Sacconi (éds), Atti e memorie del secondo congresso internazionale di micenologia II, Incunabula Graeca 98 (1996), p. 571.

123. DMIC 1, s.v. "ke-ra-me-u» (PY Cn 1287, En 467, Eo 371; MY Oe 125). De plus, l'anthroponyme féminin de ke-ra-me-ja apparaît sur KN Ap 639. Déterminer l'organisation de la production céramique selon le sexe ou l'âge des individus impliqués dans ce processus est une tentative qui apporte peu de résultats probants, voir J. Hruby, "Ke-ra-me-u or Ke-ra-me-ja? Evidence for Sex, Age, and Division of Labour among Mycenaean Ceramicists ", dans A. Brysbaert (éd.), Tracing Prehistoric Social Networks through Technology. A Diachronic Perspective on the Aegean (2011), p. 91, 101. 
$(k a-k e-u)$ et ses dérivés sur celles de Pylos et de Cnossos ${ }^{124}$, et celui d'orfèvre ( $k u-r u$-so$w o-k o$ ) sur l'une de Pylos ${ }^{125}$. L'un de ces potiers, pi-ri-ta-wo (PY En 467, Eo 371), est directement lié au palais en sa qualité de "potier royal " (ke-ra-me-u wa-na-ka-te-ro, PY Eo 371) ${ }^{126}$. Un potier, comme d'autres artisans, pouvait alors atteindre un statut élevé au sein de la société mycénienne ${ }^{127}$. Les nombreux noms de métier en linéaire B témoignent de la variété des activités menées dans le domaine de l'artisanat. Leur association à des toponymes suggère que plusieurs lieux, dont l'archéologie ne ferait que peu écho, sont susceptibles d'avoir abrité des productions et activités artisanales.

Les textes en linéaire B nous renseignent notamment sur les métaux et sur les lieux potentiels du travail du bronze à la période palatiale mycénienne. Les tablettes de la série Jn de Pylos, à l'exception de PY Jn 829 et Jn 881, sont chacune introduites par un toponyme et par la phrase "forgerons ayant un talasia», puis par un nombre d'anthroponymes auxquels correspond à chaque fois une quantité de bronze ${ }^{128}$. Sur les seize différents toponymes recensés sur les tablettes de la série $\mathrm{Jn}^{129}$, deux d'entre eux (a-ke-re-wa; $a-p u_{2}-w e$ [locatif de $\left.\left.a-p u_{2}(-d e)\right]\right)$ se rapportent à la " province proche " et l'un $(a-s i-j a-t i-j a)$ à la $"$ province lointaine ${ }^{130}$. Sur la tablette PY Jn 829, qui concerne des

124. DMIC 1, s.v. «ka-ke-u» (KN Fh 386, V 958, XN 1357; PY An 607, An 129, Jn 725, Jn 750, Na 104; MY Oe 121. Pour les forgerons de Pylos, voir D. Nakassis, Individuals and Society in Mycenaean Pylos (2013), p. 74-102.

125. DMIC 1, s.v. "ku-ru-so-wo-ko» (PY An 207).

126. Documents ${ }^{2}$, p. 246, 250; voir aussi M. H. Wiener, "Palatial Potters in Mycenaean Greece ", dans F. Lang, C. Reinholdt, J. Weilhartner (éds), Stephanos Aristeios. Archäologische Forschungen zwischen Nilos und Istros. Festschrift für Stefan Hiller zum 65. Geburtstag (2007), p. 272; J.-S. Gros, J. ZurbaCH (n. 4), p. 113. Il y a aussi un armurier et un foulon qualifiés de wa-na-ka-te-ro dans les archives pyliennes, voir P. Carlier (n. 122), p. 572.

127. P. Carlier, La Royauté en Grèce avant Alexandre (1984), p. 68-72; A. Farnoux, "Archéologie de la céramique minoenne et mycénienne ", Ramage 12 (1994-1995), p. 40.

128. Documents ${ }^{2}$, p. 352. Dans le cas des tablettes PY Jn 310 et Jn 431, des groupes de forgerons semblent travailler pour une divinité (po-ti-ni-ja-we-jo) ou être dépendants d'elle, voir PTT, p. 164, 168; Fr. Rougemont, "Textile Production and the Mycenaean Sanctuaries ", dans C. Gillis, B. SjöBerg (éds), Trade and Production in Premonetary Greece. Crossing Borders, Proceedings of the 7th, 8th and 9th International Workshops, Athens 1997-1999 (2008), p. 292.

129. Documents ${ }^{2}$, p. 355-356. Sur quinze de ces tablettes, on peut lire les toponymes suivants : $a-k e-r e-w a$, po-wi-te-ja, a-pe-ke-i-jo + a-pe-ke-e, a-ka-si-jo-ne, wi-ja-we-ra $a_{2}, o-r e-m o-a-k e-r e-u, r u-k o-a_{2}-[]-.r e-u-t e$, a-pi-no-e-wi-[jo], e-ni-pa-te-we, na-i-se-wi-jo, a-ke-re-wa +a-pu,?-we, pa-to-do-te, e-ni-pa-te-we + [.]-nu$w e-j o+n a-i-s e-w i-j o+a-k e-r e-w a, a-s i-j a-t i-j a, r o-u-s o$. On soulignera que $a-k e-r e-w a$ revient trois fois et que $a-p e-k e-i-j o$ est un ethnique. na-i-se-wi-jo revient également deux fois, dont l'une avec $a-k e-r e-w a$. Voir aussi D. NAKASsis (n. 124), p. 76-77, table 3.1.

130. Documents ${ }^{2}$, p. 416, 424, pour les neuf toponymes de la "province proche" ( $p i-{ }^{*} 82$, me-ta-pa, pe-to-no, $p a-k i-j a-, a-p u_{2}$ ?-, a-ke-re-wa, e-ra-to, ka-ra-do-ro, ri-jo) et sept toponymes de la " province lointaine" " (ti-mi-to a-ke-e, ra-wa-ra-ta, sa-ma-ra, a-si-ja-ti-ja, e-ra-te-re-wa-pi, za-ma-e-wi-ja, e-re-i), voir ibid., p. 142-143, 300-301 (PY Ng 319 et Ng 332). Voir J. Chadwick, "The Mycenaean Documents", 
tributs de bronze, sont également inscrits des toponymes. On y lit le toponyme me-ta$p a$, qui se retrouve également sur la tablette PY An 607, où deux forgerons apparaissent sur un enregistrement de femmes et d'hommes ${ }^{131}$. Me-ta-pa, a-pu $u_{2}-w e$ et $a-k e-r e-w a$ sont localisés dans la "province proche ». Ces toponymes suggèrent donc que des forgerons vivaient ou travaillaient dans des lieux proches de Pylos.

Associer les toponymes mycéniens à des lieux précis dans la configuration géographique actuelle est un autre exercice qui a toutefois déjà montré ses limites ${ }^{132}$. Il est difficile de replacer avec certitude nos trois toponymes me-ta-pa, $a-p u_{2}-w e$ et $a-k e-r e-w a$, bien que l'on sache que les deux premiers se trouvent près de Pylos et que le troisième en est bien plus éloigné ${ }^{133}$. Il se pourrait que $a-p u_{2}-w e$ corresponde à Iklaina, mais il faut attendre les résultats de nouvelles fouilles ${ }^{134}$ pour obtenir des éléments supplémentaires susceptibles de s'accorder avec les témoignages écrits.

Il est en revanche certain que d'autres toponymes se rapportent, dans les textes pyliens, à des groupes d'hommes, sans aucun doute des ouvriers. On notera que le toponyme même de Pylos apparaît sur une tablette (PY An 129) où il est question de forgerons ${ }^{135}$. Quant aux potiers et aux orfèvres, la tablette PY An 207 présente - à côté d'autres noms de lieux et de métier, tous suivis de groupes d'hommes - les toponymes re-ka-[ta]-ne et $a-n u-w a$. Chacun d'eux est associé, sur la même ligne, à l'un de ces deux noms de métier ${ }^{136}$.

Quant à Mycènes, il est question, sur deux des tablettes découvertes dans la Maison du Marchand d'huile (MY Oe 121, Oe 125), de laine attribuée soit à un forgeron (ka-ke-wi),

dans W. A. McDonald, G. R. Rapp (éds), The Minnesota Messenia Expedition. Reconstructing a Bronze Age Regional Environment (1972), p. 107; J. Bennet, "The Geography of the Mycenaean Kingdoms ", dans Y. Duhoux, A. Morpurgo Davies (éds), A Companion to Linear B. Mycenaean Greek Texts and their World, vol. 2 (2011), p. 141-143. Le toponyme a-ke-re-wa apparaît également sur une tablette (PY Jo 438) qui traite de tributs d'or, mais sans mention de forgerons ni d'orfevres, voir Documents ${ }^{2}$, p. 358-359.

131. Documents ${ }^{2}$, p. 357 (PY Jn 829), 166-167 (PY An 607).

132. J. Bennet (n. 130), p. 144.

133. J. Chadwick (n. 130), p. 106, fig. 7-1; J. Bennet (n. 130), p. 153, fig. 13.2. Pour une géographie pylienne, voir J. BENNET (n. 130), p. 151-155, en particulier p. 154 : a-ke-re-wa correspond peut-être au site archéologique de Koryfasio Beylerbey, et $a-p u_{2}$-we peut-être à Iklaina-Traganes. Voir aussi M. B. Cosmopoulos, The Political Landscape of Mycenaean States: A-pu, and the Hither Province of Pylos, AJA 110 (2006), p. 205-228, en particulier p. 217.

134. Fouilles menées sous la direction de M. B. Cosmopoulos, voir http://iklaina.wordpress.com/.

135. PTT, p. 45. Le toponyme pu-ro-jo (Gén.) est suivi d'hommes au nombre de 10. En considérant que $k a-k e-u$-si (Dat. pl.) est précédé de pa-ro, qui peut être traduit par « de la part ou aux mains de » ou encore «avec » (voir Documents ${ }^{2}$, p. 568-569; DMIC 2, s.v. «pa-ro»), on pourrait suggérer que les hommes ou groupes d'hommes enregistrés sur cette tablette constituent de la main-d'œuvre pour les forgerons.

136. Documents ${ }^{2}$, p. 182-183. Dans le cas de re-ka-[ta]-ne, il peut aussi s'agir d'un ethnique. 
soit à un potier (ke-ra-me-wi[ $)^{137}$ sans que des toponymes leur soient toutefois associés. On rappellera que ce bâtiment se trouve près de la Maison des Boucliers et de la Maison des Sphinx où un nombre important d'ivoires a été mis au jour. En outre, on ne rencontre pas de toponymes clairement indiqués sur les tablettes où il est fait mention d'ivoire, que cela soit dans le répertoire pylien ou thébain. Pourtant, les tablettes de Thèbes témoignent notamment de la circulation de matières premières comme de la laine, d'animaux et d'hommes en différents lieux ${ }^{138}$. En outre, on notera que les potiers sont rarement mentionnés sur les ablettes en regard de l'abondance de céramique retrouvée dans le monde mycénien, ce qui la distingue d'autres types de productions sur lesquelles le contrôle palatial paraît plus étendu.

Les textes en linéaire B, principalement ceux de Cnossos mais aussi ceux de Pylos et de Thèbes, nous renseignent sur les productions textiles à différents niveaux ${ }^{139}$ : de la gestion de troupeaux - dans certains cas associés à une divinité et à un lieu ${ }^{140}$ aux ouvrières ${ }^{141}$ et à l'allocation de laine à différents individus ${ }^{142}$, jusqu'à l'objet fini - les tissus (logogramme TELA) ${ }^{143}$ - et leur usage, notamment lors de cérémonies

137. Voir J. L. Melena, J.-P. Olivier (n. 115), p. 66-67. Bien que le signe LANA sur la tablette MY Oe 125 ne soit pas certain, on ne doute pas de sa restitution en raison de la série dans laquelle cette tablette s'inscrit. Pour une tablette enregistrant la distribution d'huile à des femmes et provenant de la Maison du Marchand d'huile, voir C. W. Shelmerdine, "Workshops and Record Keeping in the Mycenaean World ", dans Laffineur, Betancourt 1997, p. 390-391.

138. V. L. Aravantinos, "Mycenaean Place-Names from Thebes: the New Evidence ", dans J. T. Killen, J. L. Melena, J.-P. Olivier (éds), Studies in Mycenaean and Classical Greek Presented to John Chadwick, Minos XX-XXII (1987), p. 33-40; V. L. Aravantinos, L. Godart, A. Sacconi (n. 109), p. 355-358; M. Del Freo, "The Geographical Names in the Linear B Texts from Thebes ", Pasiphae 3 (2009), p. 41-67. Pour la laine, voir M.-L. Nosch, «The Mycenaean Textile Industry on the Kadmeia ", dans V. L. Aravantinos (éd.), Proceedings of the 4th International Congress of Boeotian Studies, held at Levadeia, Greece, September 2000 (2008), p. 195.

139. Documents ${ }^{2}$, p. 313-323 (textes cnossiens), 323 (textes pyliens). Pour le domaine économique, voir par exemple M.-L. BECH Nosch, "Acquisition and Distribution: ta-ra-si-ja in the Mycenaean Textile Industry ", dans C. Gillis, Ch. Risberg, B. SjöBerg (éds), Trade and Production in Premonetary Greece, Proceedings of the 6th International Workshop, Athens 1996 (2000), p. 43; V. P. Petrakis, "'Minoan' to 'Mycenaean': Thoughts on the Emergence of the Knossian Textile Industry ", dans M.-L. Nosch, R. Laffineur (n. 75), p. 77-86. Pour les textes thébains, voir M.-L. Nosch, "The Textile Industry at Thebes in the Light of the Textile Industries at Pylos and Knossos ", Studia minora Facultatis Philosophicae Universitatis Brunensis 6-7 (2001-2002), p. 179-191.

140. Fr. Rougemont (n. 128), p. 288-289. On citera les 100 moutons et 190 cochons recensés sur la tablette PY Cc 665, associés à po-ti-ni-ja, une divinité, et ne-wo-pe-o, un toponyme.

141. Les sources pyliennes (PY Ab 745, Ad 295, etc.) indiquent notamment la présence d'ouvrières du lin (ri-ne-ja), voir A. Bernabé, E. R. Luján (n. 111), p. 217.

142. Pour un usage de la laine dans des industries textiles, voir les séries KN L-, Od, TH Of, et MY Oe. Une série importante provient de Mycènes, voir J. L. Melena, J.-P. Olivier (n. 115), p. 63-68 (Oe 103 à 140).

143. M.-L. Nosch, "The Textile Logograms in the Linear B Tablets: les idéogrammes archéologiques - des textiles ", dans P. Carlier et al. (n. 49), p. 305-346. 
religieuses ${ }^{144}$. L'industrie textile compte des individus occupés à des tâches précises comme le filage et le foulage de la laine, le tissage ou encore la fabrication de filets ${ }^{145}$.

Un examen des exemples pyliens nous permet de souligner trois éléments importants. Tout d'abord, le toponyme Pylos est associé, sur des tablettes différentes, à des ouvrières spécialisées dans l'industrie textile, ou à leurs fils, comme des couturières (a-ke-ti-ra 2 , PY $\mathrm{Ab} 564)$ ou des fils de couturières (a-ke-ti-ra $a_{2}-o$, PY Ad 666), de fileuses de laine (a-ra-kate-ja-o, PY Ad 380, Ad 677), de tisserandes (i-te-ja-o, PY Ad 684) et d'ouvrières du lin (ri-ne-ja-o, PY 664), ainsi que des cardeuses de laine (pe-ki-ti-ra, PY Ab 578) ${ }^{146}$. Aucun autre toponyme ne présente une telle diversité d'associations.

Trois autres toponymes apparaissent sur des tablettes faisant mention d'ouvrières spécialisées : celui de Leuktron (re-u-ko-to-ro), associé à des fils de couturières $(a-k e-t i-$ $r a_{2}-o$, PY Ad 290) et d'ouvrières du lin (ri-ne-ja-o, PY Ad 326) ${ }^{147}$, localisé dans la province lointaine de Pylos ${ }^{148}$, celui de Lousoi (ro-u-so), associé à 32 couturières (a-ke-ti-ri-ja, PY Aa 717), et celui de Korinthos (ko-ri-to), mentionné avec des fils de fabricantes de te-pa (te-pe-ja-o, PY Ad 921). Les deux premiers rappellent des sites connus en Arcadie. Si l'on admet que des places ont porté les mêmes noms en Messénie, leur mention sur ces tablettes, en particulier en ce qui concerne celui de ko-ri-to, ne peut alors pas être interprétée comme le signe d'une emprise pylienne s'étendant jusqu'à Corinthe ${ }^{149}$. En revanche, le nombre élevé de couturières et le fait que ro-u-so apparaisse, sur une autre tablette, en relation avec des forgerons ( $k a-k e-w e$, PY Jn 832) ${ }^{150}$ suggèrent que cette localité entretenait de forts liens ou dépendait de Pylos en matière d'artisanat.

Enfin, les fils d'ouvrières du lin, qui sont associés aux toponymes de Pylos et de Leuktron, le sont aussi à ceux de e-u-de-we-ro, e-pi-ko-e (PY Ad 672), po-to-ro-wa-pi (PY Aa 76), Je-pi-ja-ta-ni-ja (PY Ad 687) et da-mi-ni-ja (PY Ad 697) ${ }^{151}$. La diversité des toponymes pourrait être interprétée comme le signe d'une décentralisation des tâches liées au traitement du lin dans plusieurs localités du royaume pylien.

144. Pour le festival te-o-po-ri-ja, voir J. Gulizio, «Textiles for the Gods? Linear B Evidence for the Use of Textiles in Religious Ceremonies ", dans M.-L. Nosch, R. Laffineur (n. 75), p. 279-285.

145. A. Morpurgo Davies (n. 122), p. 99-100; à compléter par V. L. Aravantinos, L. Godart, A. Sacconi (n. 109), s.v. «ka-na-pe-we», «o-nu-ke-wi», «o-ti-ri-ja-i», "pe-re-ke-we», p. 322-323.

146. On trouve également des o-nu-ke-ja (PY Ab 194) et des fils de o-nu-ke-ja-o (PY Ad 675) dont il est difficile de proposer une traduction.

147. Documents ${ }^{2}$, p. 159. Il y a également des fils de no-ri-wo-ko-jo (PY Ad 669) à re-u-ko-to-ro.

148. J. СHADWICK (n. 130), p. 107.

149. M. B. Cosmopoulos (n. 133), p. 209.

150. Pour les termes liés à l'artisanat des métaux, voir A. Morpurgo Davies (n. 122), p. 101. Pour un dérivé du toponyme ro-u-so inscrit sur un document provenant du Bâtiment Nord-Est de Pylos, voir L. M. Bendall (n. 93), p. 218.

151. Pour Eudeiwelos (e-u-de-we-ro), voir Documents' ${ }^{2}$, p. 159. 


\section{2. ESPACES DE PRODUCTION TEXTILE ET POLYVALENCE DES ESPACES}

Malgré les indications géographiques fournies par les textes mycéniens et les pesons de fuseau fréquemment trouvés en contexte domestique, on peine à identifier des espaces de production textile majeurs dans les habitats mycéniens. Le contraste entre sources écrites et données archéologiques mérite d'être souligné. On aurait par exemple souhaité retrouver des ateliers de l'industrie textile à Pylos ${ }^{152}$. Aucun aménagement spécifique prévu à cet effet n'a jusqu'à présent été clairement identifié dans les sites palatiaux ${ }^{153}$.

En revanche, au niveau du mobilier, les traces de cette production se remarquent de manière plus tangible dans la citadelle basse de Tirynthe où un nombre important d'outils utilisés dans l'industrie textile a été recueilli ${ }^{154}$. Il s'agit en majorité de pesons de fuseau et de tessons arrondis et percés utilisés à cette fin, ainsi que de bobines. Dispersés dans plusieurs maisons, ces objets seraient les indices d'activités artisanales effectuées dans le cadre domestique. Cependant, la concentration de tels outils en deux endroits suggère l'existence d'une production artisanale dont l'ampleur dépasse ce cadre. On soulignera leur contexte post-palatial.

Une des pièces de l'aire Ouest, bâtie contre le mur de fortification, semble avoir concentré des activités liées au tissage à l'HR III C récent, comme le suggère la découverte de cinq bobines en terre dans cet espace ainsi que d'autres bobines et de tessons arrondis et percés retrouvés à proximité de cette maison ${ }^{155}$. Une autre pièce de l'aire Ouest, plus au Sud, occupée à l'HR III C moyen et récent, se distingue également par la présence de ces types d'outils issus de phases d'occupation successives ${ }^{156}$, peut-être liés au matériel d'une fosse voisine comprenant entre autres 17 bobines ${ }^{157}$. À ces deux ensembles s'ajoute encore la vingtaine de bobines retrouvées sur les restes d'un sol assignés au Submycénien dans l'aire Nord-Ouest ${ }^{158}$.

152. D'autres "absences" peuvent être notées : celle de four durant la phase palatiale, contrairement à l'HR I-II, et celle d'outils de forgerons sur ce site, déjà soulignée par C. Gillis, "The smith in the Late Bronze Age - State employee, independent artisan, or both? ", dans Laffineur, Betancourt 1997, p. 508.

153. Hors de sites palatiaux, des canaux mis au jour à Kontopigado (Attique) ont peut-être été utilisés pour le traitement du lin, voir K. Kaza-Papageorgiou et al. (n. 34), p. 201-204, fig. 2; voir aussi p. 266.

154. Rahmstorf 2008, p. 235, 289-290.

155. Ibid., p. 267 (R 112).

156. Ibid., p. 276-278 (R 127). Pour la pièce R 127, voir K. Kilian, « Ausgrabungen in Tiryns 1981. Bericht zu den Grabungen », $A A$ 1983, p. 281-282.

157. Rahmstorf 2008, p. 279 (+ 2 skyphoi et deux tessons arrondis). La découverte de bobines n'est pas rapportée mais celle de trois skyphoi l'est dans K. KILIAN, "Ausgrabungen in Tiryns 1977. Bericht zu den Grabungen ", $A A 1979$, p. 386.

158. Rahmstorf 2008, p. 250-251 (26 bobines en LXII 36/63-64); voir K. Kilian (n. 5, 1988), fig. 4 citée p. 107. 
Rares sont les autres assemblages attestés sur le continent d'outils significatifs qui indiquent l'existence d'une production textile importante à l'endroit même de leur découverte. Le Grenier de Mycènes, tout d'abord, qui a livré 35 bobines en terre cuite, une en os, 13 conuli en pierre, 2 conuli en terre cuite et 2 aiguilles ou épingles en os, a certainement compris un espace de production de ce type à l'HR III C ${ }^{159}$.

Différents endroits de la Cadmée de Thèbes ont pu également abriter des espaces de production textile. On citera la découverte de 23 pesons de fuseau dans l'espace bâti du terrain Kofini, détruit à l'HR III B2, où d'autres types d'activités artisanales ont également pu être conduits, comme peut-être le travail de l'ivoire ${ }^{160}$. De plus, des pesons de fuseau et 8 aiguilles ou épingles en os proviennent des niveaux HR III C de la rue Pélopidou ${ }^{161}$. Enfin, la trentaine d'outils liés à l'industrie textile découverts sur le côté oriental de la Cadmée, dans le "Complexe Est » ${ }^{162}$, suggèrent davantage l'existence d'une production textile majeure in situ que la découverte de petits pesons de fuseau dans le terrain SoteriouDougekou, dans un terrain où le traitement de la laine à l'HR III B2 est possible ${ }^{163}$.

Alors que l'on pourrait s'attendre à davantage d'exemples de l'HR III B2 en Grèce mycénienne, c'est à nouveau un dépôt plus récent, de l'HR III C moyen, qu'il convient d'ajouter aux espaces susceptibles d'avoir abrité des activités importantes liées à la production textile. Au moins 22 bobines en terre cuite se trouvaient en effet amassées dans un bâtiment de Kynos (Livanatès-Pyrgos) en Phthiotide ${ }^{164}$.

On peut supposer que les productions étaient davantage réparties en petites et moyennes unités plutôt que concentrées en des ateliers majeurs où la chaîne opératoire de traitement et de fabrication des matériaux se reconnaîtrait bien sur le plan archéologique. Il n'est toutefois pas vain de considérer de manière conjointe les espaces de production

159. P. DARCQue (n. 1), p. 193-194. Le bâtiment est occupé jusqu’à l'HR III C moyen. Les conuli regroupent les objets nommés whorl, spindle whorl, steatite whorls dans A. J. B. WACE, « Excavations at Mycenae. 2. The Granary », BSA 25 (1921-23), p. 54.

160. Alberti et al. 2012, p. 89.

161. Ibid., p. 92. Ces outils correspondent sans doute aux découvertes rapportées par V. L. Aravantinos,

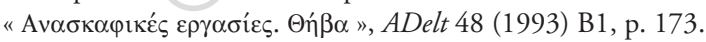

162. Alberti et al. 2012, p. 94. Dans le terrain Christodoulou : une trentaine d'outils de l'industrie textile, principalement des pesons de fuseau et des poids de métier à tisser, attribués à des phases allant de l'HM à la fin de l'HR. Dans le terrain Stamatis : 15 pesons de fuseau, trois poids de métier à tisser et des instruments en os.

163. Un canal et une rangée de fosse pourraient, selon le fouilleur, correspondre aux restes d'une installation pour laver et sécher la laine mais cette interprétation repose essentiellement sur la découverte de tablettes en linéaire B traitant de la laine. Voir Th. G. Spyropoulos, J. Chadwick, The Thebes Tablets II (1975), p. 22. Pour les pesons de fuseau, voir ibid., p. 37, fig. 12. La présence d'un atelier est réfutée par C. W. Shelmerdine (n. 137), p. 387-389, Demakopoulou 2014, p. 144 . Pour la conduite de telles activités, voir AlberTi et al. 2012, p. 95.

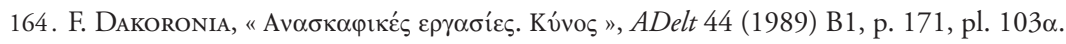


artisanale qui se distinguent soit par la présence de fours, soit par celle d'assemblages de mobilier spécifique. Pour le cas de Thèbes, cet examen confirme la polyvalence des espaces où des traces d'activités artisanales ont été identifiées à l'HR III B ${ }^{165}$.

De plus, les découvertes en terres béotiennes montrent que les espaces étudiés se concentrent à l'HR III B dans un seul site, à Thèbes (tabl. I). Sur la Cadmée, on suppose la conduite d'activités artisanales diverses à l'HR III B1 (travail de l'ivoire, orfèvrerie, activités métallurgiques, production textile, production céramique probable). En revanche, durant cette phase, en Argolide, les productions et activités artisanales se distinguent de manière plus prononcée selon le site étudié. Elles sont représentées par la transformation de l'ivoire à Mycènes, des activités métallurgiques à Tirynthe, une production céramique à décor figuré à Berbati - bien que le four de ce site ne soit plus en fonction à l'HR III B - et peut-être une production céramique commune à Asinè. Pour la phase HR III B2, cette image peut être complétée par le travail de l'ivoire et de

\begin{tabular}{|c|c|c|c|c|c|c|}
\hline Site & Terrain / Maison & Fours & Outils & Ivoire & Pierre & Datation \\
\hline \multicolumn{7}{|c|}{ Béotie } \\
\hline \multirow[b]{6}{*}{ Thèbes } & terrain A. Kordatzis & $\mathrm{m}$ & + & + & + & HR III B(1?) \\
\hline & terrain frères Tzortzis & & + & + & & HR III B1 \\
\hline & terrain M. Loukos & & + & + & & HR III B1 \\
\hline & terrain Koropoulis & & + & & + & HR III B1 \\
\hline & terrain D. Liagas & & + & - & & HR III B2 \\
\hline & Maison de Kadmos & $\mathrm{p}$ & & & + & HR III A-B1 \\
\hline \multicolumn{7}{|c|}{ Argolide } \\
\hline \multirow[b]{3}{*}{ Mycènes } & Maison des Boucliers & & + & + & & HR III B1 \\
\hline & Maison des Sphinx & & + & + & & HR III B1 \\
\hline & Maison des Artisans & & + & + & + & HR III B2 \\
\hline Midéa & zone 3 & & + & - & + & HR III B2 \\
\hline Tirynthe & Unterburg & $\mathrm{m}$ & + & & & HR III B1 \\
\hline
\end{tabular}

Fours : fours artisanaux, de potier $(\mathrm{p})$, métallurgique $(\mathrm{m})$.

Outils : outils en métal ou en pierre polie $(+)$.

Ivoire : objets semi-finis ou fragments d'ivoire (+), objets finis uniquement (-).

Pierre : objets semi-finis ou fragments non travaillés de pierre précieuse ou semi-précieuse $(+)$.

Tableau I — Exemples de contextes artisanaux à l'HR III B (Béotie, Argolide)

165. Alberti et al. 2012, p. 97 («Multi-functional work units»). 
la pierre semi-précieuse à Mycènes et probablement le travail de pierres semi-précieuses à Midéa. Il pourrait ainsi y avoir des modes de production artisanale et de circulation des biens différents selon les régions.

Bien entendu, cette interprétation demeure fragile puisque les sites, à l'image de la citadelle de Midéa, sont loin d'avoir été fouillés dans leur intégralité. De même, la découverte d'un four de potier à Mycènes pourrait modifier notre interprétation. D'autres habitats sont en cours de fouille, comme ceux de Kirrha en Phocide et d'Aigeira en Achaï. Enfin, on souhaiterait mieux comprendre l'organisation spatiale de la production artisanale sur le côté oriental du site de Dimini en Thessalie, ainsi que la configuration des vestiges de l'habitat mycénien à Kynos en Phthiotide à la lumière de nouvelles publications.

\section{COMPARAISONS AVEC LA GRÈCE MÉSOHELLADIQUE ET LA CRÈTE MINOENNE}

\section{1. UNE TRADITION MÉSOHELLADIQUE PEU SUIVIE}

Un dernier point mérite d'être discuté. On se demandera quel critère a motivé le choix de l'implantation des espaces de production au sein des habitats mycéniens. Il s'agit de cerner, par les exemples les plus pertinents, si ce choix repose sur une tradition héritée de l'HM, s'il s'inspire d'un modèle étranger ou s'il fait partie d'une réorganisation de l'habitat au cours de l'HR.

Peu d'arguments peuvent être avancés pour soutenir la thèse d'une filiation entre espaces de production céramique de l'HM et de l'HR. Excepté à Kirrha, où des fours de potier ont été installés vraisemblablement depuis l'HM sur le côté Est de la magoula préhistorique, les autres fours mésohelladiques n’ont pas été découverts dans les mêmes sites que ceux de l'HR ${ }^{166}$. On rappellera que les installations successives de fours artisanaux à Tirynthe s'opèrent au cours de l'HR III B et III C et non auparavant.

La découverte de fours de potier remontant à l'HM est recensée, hormis à Kirrha, sur l'Aétos de Sparte (Laconie) ${ }^{167}$, à Marathon-Plasi ${ }^{168}$ et à Zarkos (Trikala) ${ }^{169}$. Le four de potier mis au jour à Érétrie (Eubée) pourrait venir s'ajouter à cette liste, mais sa datation

166. Hasaki 2002, pl. IV.17. On notera que des fours domestiques (ovens) du Néolithique sont également compris parmi les fours préhistoriques recensés par l'auteur sur cette carte de répartition.

167. H. W. Catling, «Sparta: Menelaion », ADelt 35 (1980) B1, p. 153, fig. 3, pl. 57a.

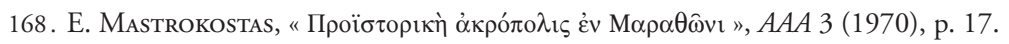

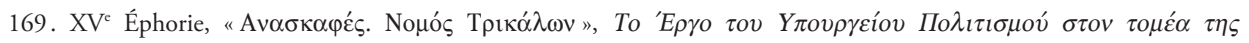

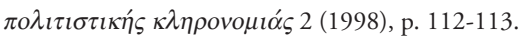


reste discutée ${ }^{170}$, ainsi qu'un autre four, peut-être, à Haghios Elias ${ }^{171}$ près de Mycènes, mais son caractère artisanal n'est toutefois pas confirmé. L'usage d'un four de potier mis au jour dans une maison à Kolonna sur l'île d'Égine ${ }^{172}$ remonte également au Bronze Moyen, mais sa production semble avoir été davantage en lien avec la Crète minoenne qu'avec le continent : un tour de potier de type minoen et de la céramique rappelant les productions crétoises lui sont en effet associés.

Quant aux fours métallurgiques recensés en contexte HM, deux sites peuvent être ici mentionnés. Le premier est le site de Nichoria en Messénie où des restes de structures mis au jour dans l'habitat HM I ont été interprétés comme des foyers mais présentent une forme en fer à cheval similaire à celle de fours ${ }^{173}$. Le second est l'habitat de Lerne en Argolide où un four HM a probablement servi à la production métallurgique ${ }^{174}$. Là encore, ce ne sont pas les sites qui comprennent des fours en contexte HR.

Enfin, il est très rare de trouver des assemblages particuliers faits de matière première, d'objets partiellement travaillés et d'outils en contexte HM. On citera l'exemple d'Eutrésis où un jeu d'appliques en dents de sanglier, des perçoirs en os, des fragments de nacre, des os partiellement travaillés, une "boîte à feu " et un ciseau en pierre ont été mis au jour dans la maison $\mathrm{E}^{175}$. En l'absence de dépôts significatifs provenant des niveaux HR de ce site, l'hypothèse d'une parenté entre espaces de production HM et HR doit là aussi être écartée, bien que les dents de sanglier constituent un matériau prisé dans le monde mycénien, notamment pour la fabrication de casques ${ }^{176}$.

\section{2. De RARes Points Communs aVec la CRÈte minoenne}

Il est difficile de trouver des points communs entre les espaces de production artisanale identifiés sur le continent et ceux qui l'ont été en Crète, alors que la Crète minoenne - qui

170. Pour une datation HM, voir Hasaki 2002, p. 83, 518, n 103. Pour une datation HA III-HM I, voir A. Tuor, « Eretria. Ausgrabunen 1979-1980. Zur bronzezeitlichen Siedlung in G10 », AntK 24 (1981), p. 83, fig. 8; id., "Eretria. Ausgrabungen 1981. Zur bronzezeitlichen Siedlung in G10 », AntK 25 (1982), p. 158-159. Pour les résultats d'analyses indiquant une date au cours de la période géométrique, voir S. MüLler CelKA, "Analyse OSL du four de potier trouvé dans la parcelle Bouratza », AntK 57 (2014), p. 78.

171. A. J. B. WACE, Mycenae. An Archaeological History and Guide (1964), p. 47.

172. H. B. Siedentopf, Mattbemalte Keramik der mittleren Bronzezeit, Alt-Ägina 4,2 (1991), p. 10.

173. R. J. Howell, "Middle Helladic Settlement: Stratigraphy and Architecture ", dans W. A. McDonald, N. C. Wilkie (éds), Excavations at Nichoria in Southwest Greece. II. The Bronze Age Occupation (1992), 26-27, fig. 2-7.

174. J. L. CASKey, «Excavations at Lerna, 1955 », Hesperia 25 (1956), p. 159, pl. 41a (furnace).

175. H. Goldman, Excavations at Eutresis in Boeotia (1931), p. 54, fig. 57 (maison), fig. 252, 290 (mobilier).

176. J.-Cl. Poursat 1977, p. 54-57; O. Krzyskowska, Ivory and Related Materials. An Illustrated Guide, Classical Handbook 3 (1990), p. 47-49, 75, pl. 18-19. 
connaît un essor considérable au cours du Bronze Moyen, notamment par l'édification de palais - pourrait avoir été une source d'inspiration pour l'aménagement de tels espaces dans les habitats mycéniens. Les exemples discutés dans cet article, loin d'être exhaustifs, auraient pu servir de modèles au continent.

On recense, dans le Quartier Mu de Malia qui couvre plus de $3000 \mathrm{~m}^{2}$, près d'une centaine de pièces, sans compter celles d'un étage supérieur, parmi lesquelles se trouvent des bâtiments désignés comme des ateliers ${ }^{177}$. Leur fonction artisanale est indéniable au vu du mobilier mis au jour. On citera la découverte d'un tour et les fragments d'un second, de moules et de séries de vases dans l'Atelier de Potier ${ }^{178}$, de moules, d'outils et de résidus métallurgiques dans l'Atelier de Fondeur ${ }^{179}$, de sceaux, d'ébauches, de pièces de rebut, de fragments de stéatite et d'outils dans l'Atelier de Sceaux ${ }^{180}$. Il est plus difficile de reconnaitre le domaine de spécialisation de l'Atelier Sud et celui du Bâtiment C, même si la fonction artisanale de ces espaces parait évidente ${ }^{181}$. Le nombre et la diversité des ateliers ainsi que l'organisation et la datation de cet ensemble qui appartient au MM II (1800-1700 av. J.-C.) offrent un exemple de contexte artisanal bien différent de ce que l'on a vu pour le continent au Bronze Récent ${ }^{182}$. Deux remarques principales peuvent toutefois être émises au sujet de ces ateliers, qui pourraient révéler de possibles points communs avec nos exemples continentaux mycéniens.

La première porte sur l'emplacement des ateliers du Quartier Mu. Leur installation conjointe au MM II ne semble pas être dictée par l'existence d'espaces de production antérieurs dans la même aire ${ }^{183}$. Un phénomène semblable a été noté pour la plupart des exemples mycéniens examinés dans cet article. Néanmoins, le Quartier Mu était déjà occupé au MM I B par deux bâtiments importants, tout comme le palais situé au SudEst du Quartier Mu. Le fait que les ateliers se trouvent à distance du palais rappelle la configuration de l'HR III B observée à Mycènes où la Maison des Boucliers et la Maison des Sphinx font partie d'un groupe de bâtiments situés au Sud-Ouest de la citadelle. Le palais de Malia n'est toutefois pas un site d'acropole fortifié, contrairement à Mycènes.

La seconde concerne le caractère polyvalent des ateliers du Quartier Mu. Outre le fait que du matériel a pu y être entreposé, par exemple à l'étage ${ }^{184}$, les bâtiments ont

177. Quartier Mu III; J.-Cl. Poursat (dir.), Vie quotidienne et techniques au Minoen Moyen II. Fouilles exécutées à Malia. Le Quartier Mu V, ÉtCrét 34 (2013), plan 1.

178. Quartier Mu III, p. 23-43.

179. Ibid., p. 45-57.

180. Ibid., p. 7-22.

181. Ibid., p. 1, 59, 69. Atelier Sud : vase en pierre inachevé, des restes de métal et d'os. Bâtiment C : moule, outils en pierre.

182. Pour la notion d'artisanat groupé, voir ibid., p. 150.

183. Ibid., p. 151.

184. Ibid., p. 43 et fig. 21 à p. 40. 
abrité des activités quotidiennes de toutes sortes dont l'outillage ne se distingue parfois pas de celui qui a été utilisé pour des tâches spécialisées ${ }^{185}$. Selon J.-Cl. Poursat, il s’agit d'un ensemble groupé de maisons d'artisans, qu'il nomme " maisons-ateliers ", puisque des pièces d'habitation y ont été identifiées ${ }^{186}$. Les outils de mouture recueillis dans ces ateliers minoens ${ }^{187}$ se rapportent à un cadre domestique. La fonction multiple des bâtiments rappelle un phénomène observé dans la Maison des Sphinx à Mycènes, d'où proviennent également quelques outils de mouture ainsi que des centaines de vases ${ }^{188}$.

Un point intéressant peut encore être souligné en ce qui concerne le Quartier $\mathrm{Mu}$ de Malia. Bien que cette zone artisanale comprenne un atelier de fondeur, « le lieu de travail proprement dit - la zone des fours et de la fusion du métal - n'a pas été découvert à ce jour ${ }^{189}$ ". De plus, il a déjà été observé que les outils du fondeur correspondent souvent à des éléments isolés et disséminés sur un même site ${ }^{190}$. L'hypothèse d'un lieu de production métallurgique proche mais différent de celui du lieu de montage pourrait alors être émise, à Malia comme à Gournia, en Crète, où le travail du bronze est attesté sans que sa production le soit au MR I B ${ }^{191}$.

Un four a pourtant été mis au jour dans la Maison Thêta du quartier IV à Malia, près de la mer ${ }^{192}$, probablement destiné à la production céramique au MM II/III ${ }^{193}$, puisqu'un tour de potier a été découvert dans ce bâtiment. Cette association, que l'on retrouve par exemple à Vathypetro ${ }^{194}$, montre que le four ne se trouve pas en contexte artisanal isolé, contrairement à ce que l'on a remarqué pour les exemples mycéniens. En outre, c'est en Crète, à Gouvès, près de Malia, que le plus grand nombre de fours de potier mis au jour dans un même site égéen - à savoir neuf exemplaires couvrant une période allant du MM II au MR III B ${ }^{195}$ - a été recensé. Il ne s'agit pas ici de s'attarder sur l'ensemble des

185. Voir J.-Cl. Poursat (n. 177, 2013), p. 193-195.

186. Quartier Mu III, p. 30-31, fig. 14-16.

187. H. Procopiou, «Les outils lithiques », dans J.-Cl. Poursat (n. 177, 2013), p. 45, pl. II.2.

188. Tournavitou 1995, p. 69-121 (céramique), p. 232 (outils en pierre). Voir aussi T. Whitelaw (n. 45), p. 64.

189. Quartier Mu III, p. 45.

190. С. Овerweiler, «Les techniques de fonderie en Crète minoenne et mycénienne. I. Les outils du fondeur ", BCH 135 (2011), p. 432.

191. Evely 2000, p. 335-338, fig. 133.

192. H. et M. Van Effenterre, Fouilles exécutées à Mallia. Exploration des maisons et quartiers d'habitation (1956-1960), ÉtCrét 22 (1976), p. 31, 66, pl. XXX, XXXII. Cette maison a été interprétée comme atelier par les fouilleurs en raison de la découverte d'outils.

193. Identification acceptée par EveLY 2000, p. 300, 312; incertaine pour HASAKI 2002, p. 430.

194. Evely 2000, p. 312.

195. D. Vallianou, "The Potters' Quarter in LM III Gouves», dans Laffineur, Betancourt 1997, p. 333-344. Neuf fours, des bassins et des fragments de tours. 
fours de potier trouvés en Crète minoenne ${ }^{196}$, mais on notera que de telles découvertes dans des sites relativement isolés, loin d'autres établissements, s'observent également en Crète ${ }^{197}$.

Un autre four a été mis au jour à Zakros. Dans le palais même, détruit au MR I B, plusieurs pièces ont pu abriter des activités artisanales et non pas seulement servir à l'entreposage de matières brutes et d'outils ${ }^{198}$. La pierre comme la stéatite était travaillée dans certaines pièces, mais les activités artisanales menées dans d'autres pièces étaient de nature variée. Les espaces de travail identifiés dans le palais de Zakros permettent à L. Platon de formuler des observations générales sur la place des activités artisanales dans les palais minoens ${ }^{199}$. Les contextes artisanaux de Zakros peuvent difficilement être comparés à ceux de Grèce mycénienne, mais on soulignera toute de même un point commun : les pièces de petites dimensions ont pu là aussi abriter divers types de travail artisanal.

Enfin, on ne peut quitter la Crète sans parler de Cnossos, où la découverte de quatre fours et de différentes aires de travail est rapportée. Trois des fours du MR II situés dans le quartier Ouest de ce site palatial ont été identifiés comme des fours à chaux tandis qu'un quatrième du MM II/III A, à l'angle Sud-Est du palais, a peut-être servi à produire de la faïence ${ }^{200}$. En comparaison, ce n'est pas quatre mais deux fours qui auraient pu, à Thèbes, remplir des fonctions similaires, l'un, accolé à la Maison de Kadmos, était sans doute destiné à la production céramique et réutilisé pour celle de la chaux ${ }^{201}$; l'autre était employé pour la chauffe et la soudure d'éléments métalliques ${ }^{202}$ ainsi que, peut-être, pour la production de pâte de verre à l'HR III $B$.

En ce qui concerne la céramique, on notera la découverte, dans la partie Nord-Est du palais de Cnossos, de masses de déchets comprenant des tasses et des tessons du MM III ${ }^{203}$ qui évoquent davantage un espace de stockage voisin qu'une aire de travail.

196. Pour Phaistos, on se rapportera à L. Platon (n. 1), p. 109-110; Evely 2000, p. 298-311 ; F. M. Carinci, "Pottery workshops at Phaestos and Haghia Triada in the Protopalatial period", dans Laffineur, Betancourt 1997, p. 317-322; pour Kommos, voir J. W. Shaw, A. Van de Moortel, P. M. Day, V. Kilikoglou, "A LM IA Pottery Kiln at Kommos, Crete ", dans Laffineur, Betancourt 1997, p. 323-331.

197. Hasaki 2002, p. 202.

198. L. Platon (n. 1), p. 113-119.

199. Ibid., p. 120-121.

200. Evely 2000, p. 300, 304; voir le rapport de M. S. F. Hood dans ARepLond (1957), p. 24, fig. 6b ; voir aussi $B C H 82$ (1958), p. 784, fig. 12.

201. HASAKI 2002, p. 123.

202. Symeonoglou 1973, p. 12, 15, 63.

203. A. Evans, The Palace of Minos. A Comparative Account of the Successive Stages of the Early Cretan Civilization as Illustrated by the Discoveries at Knossos. I. The Neolithic and Early and Middle Minoan Ages (1921), p. 387, 391; aire de travail discutée, voir Evely 2000, p. 317. 
On se demandera que sont devenus là les outils du potier et, dans le cas de l'Atelier du lapidaire (Lapidary's Workshop), les outils du tailleur, dont l'aire de travail est supposée se trouver à l'étage situé au-dessus d'une réserve de blocs de basalte importés de Laconie, en raison de la découverte de deux vases en pierre inachevés ${ }^{204}$. Peu de parallèles entre ces exemples et ceux du continent peuvent être établis, si ce n'est la présence d'espace de travail à l'étage des bâtiments examinés.

En revanche, l'atelier de la Route Royale (Royal Road) de Cnossos offre un bon élément de comparaison aux Maison des Boucliers et Maison des Sphinx de Mycènes. La découverte de plus de 4000 pièces d'ivoire - parmi lesquelles des objets finis, d'autres inachevés et des débris, ainsi que divers outils en bronze ${ }^{205}$ - apporte la preuve indéniable d'une aire de travail importante, sans doute située à l'étage du bâtiment MR I B ${ }^{206}$.

On citera finalement l'existence d'une dernière aire de travail au Nord-Ouest du palais, la plus récente des exemples cnossiens, qui ne trouve toutefois pas de parallèle probant sur le continent. Dans la "Maison Inexplorée " (Unexplored Mansion) du MR II, on recense la découverte de débris et d'outils dont certains sont caractéristiques du travail de forge (tuyère, creusets) et d'autres pourraient avoir servi au façonnage de modèles en cire employés dans le procédé de moulage destiné à la fonte de métaux ${ }^{207}$.

\section{CONCLUSION}

Alors que la Crète palatiale connaît, dès le Bronze Moyen, un essor culturel considérable qui, dans le domaine artisanal, se distingue à Malia par l'implantation d'un ensemble groupé de plusieurs maisons d'artisans, la Grèce mésohelladique est loin de suivre le même développement. À cette période, les habitats continentaux sont bien plus modestes

204. A. Evans, The Palace of Minos. A Comparative Account of the Succesive Stages of the Early Cretan Civilization as Illustrated by the Discoveries at Knossos. III. The Great Transitional Age in the Northern and Eastern Sections of the Palace: the most Brillant Records of Minoan Art and the Evidences of an Advanced Religion (1930), p. 269, fig. 183. La même remarque vaut pour la fabrication de vases au-dessus du magasin XIII étudiée par P. WArren, "A Stone Vase Maker's Workshop in the Palace at Knossos ", BSA 62 (1967), p. 195-199. Voir aussi L. Platon (n. 1), p. 109.

205. Tournavitou 1995, p. 191.

206. R. D. G. Evely (n. 70), p. 224; voir M. S. F. Hood, "Archaeology in Greece ", ARepLond (1960-61), p. 26-27; id., "Archaeology in Greece ", ARepLond (1961-62), p. 27.

207. On suivra l'interprétation de Evely 2000, p. 338, qui relève dans cette aire de travail l'absence d'éléments essentiels à la production métallurgique, bien que l'existence d'un atelier soit soutenue par H. W. Catling, E. Catling, "The Bronzes and Metalworking Equipment ", dans M. R. Рopham (éd.), The Minoan Unexplored Mansion at Knossos, BSA Supplementary 17 (1984), p. 203-222. 
que ceux de l'île et les espaces de production artisanale se répartissent dans des sites différents de ceux de l'Helladique Récent.

En outre, les traces d'un "artisanat groupé " tel qu'on l'observe à Malia ${ }^{208}$ ne se retrouvent pas en Grèce mycénienne. La citadelle basse de Tirynthe, qui comprend certes une zone artisanale caractérisée par la présence de fours métallurgiques et de potier en contexte HR III B et HR III C installés près du mur de fortification, ne permet pas de supposer un lien de parenté avec un modèle crétois. Ce constat ne signifie toutefois pas que les points communs entre le continent et la Crète sont inexistants. On rappellera que divers types d'activités artisanales ont pu être menés dans un même espace de petites dimensions. Le travail de l'ivoire, primaire ou secondaire, à Cnossos au MR II comme à Mycènes à l'HR III B1 s'est déroulé à l'étage de bâtiments situés à quelque distance des palais respectifs.

La majorité des espaces de production artisanale mycéniens fait vraisemblablement partie d'une réorganisation de l'habitat à l'HR III. Seul le site de Kirrha présente une installation successive de fours de potier de l'HM à l'HR III sur son côté Est, mais ne suffit pas à confirmer l'hypothèse d'un héritage mésohelladique dans l'organisation spatiale de la production artisanale mycénienne. De plus, on ne recense pas avant l'HR III B1 l'existence de fours métallurgiques et d'aires de travail de l'ivoire dans des habitats mycéniens.

Au cours de l'HR III B, les espaces de production et d'activités artisanales sont bien intégrés aux habitats mycéniens. Ils se trouvent à proximité ou à l'intérieur d'aires bâties et, dans plusieurs cas, avoisinent avec des espaces de fonction différente tels des lieux de stockage comme à Thèbes. Bien évidemment, la distinction entre aire de travail et d'entreposage de mobilier repose sur la composition des assemblages mis au jour et le degré d'exhaustivité des éléments représentés, c'est-à-dire d'outils, d'objets semi-finis, de matières premières ou de chutes. Aires de travail artisanal et espaces domestiques peuvent également coexister dans les mêmes bâtiments, comme on le suppose par exemple pour la Maison des Sphinx à Mycènes. Les productions concernées peuvent, en outre, être de nature variée, comme c'est le cas à Thèbes où des traces d'activités textile et de travail de l'ivoire ont été identifiées. La fonction polyvalente - ou multi-fonction ${ }^{209}$ - des espaces considérés est un trait caractéristique des bâtiments qui abritent des activités artisanales.

Le caractère isolé des fours artisanaux a néanmoins été souligné. Rares sont les structures complémentaires que l'on peut leur associer, comme par exemple un dépotoir à Berbati ou un assemblage significatif, comme à Thèbes, où des objets semi-finis et des outils ont notamment été découverts dans le terrain A. Kordatzis. De là, on peut

208. Voir Quartier Mu III, p. 150.

209. Voir Alberti et al. 2012, p. 97. Voir aussi A. Dakouri-Hild (n. 75), p. 475 ("multimedia workshops "). 
s'interroger sur les modes d'utilisation de l'espace réservé à la production artisanale et émettre l'hypothèse de zones de productions céramique et métallurgique permanentes qui n'auraient toutefois été en fonction qu'à certains moments de l'année. Les métaux ont également pu être chauffés dans des foyers, comme le suggèrent les exemples de Tirynthe. On doutera en revanche que la mise en forme des objets en métal se déroulait là où le minerai était transformé en métal.

Il est difficile de déterminer sur des critères archéologiques si les artisans emportaient leur matériel et leurs outils avec eux, si ceux-ci circulaient d'un établissement à un autre pour offrir leur service et trouvaient là du matériel brut, des objets semi-finis ou des éléments à assembler. De plus, on ne peut exclure que les artisans travaillaient plusieurs matières ${ }^{210}$. Les sources écrites mycéniennes rapportent que des forgerons sont associés à différents lieux du royaume pylien dont le nombre pourrait s'élever à 400 individus ${ }^{211}$. Cette estimation pourrait toutefois couvrir l'ensemble des hommes impliqués dans la production métallurgique et non pas seulement le nombre de forgerons proprement dits. En outre, de nombreux lieux et espaces abritant des activités artisanales telles que le travail des peaux, de l'osier et du bois demeurent inconnus alors que les textes mycéniens mentionnent des noms de métier divers.

Cependant, les données archéologiques attirent l'attention sur un autre phénomène. En Béotie, la coexistence d'espaces de production artisanale divers à Thèbes pourrait correspondre à une centralisation des activités socio-économiques sur la Cadmée à l'HR III B tandis que leur répartition différenciée sur des établissements tels que Mycènes, Tirynthe, Midéa et Berbati se rapporterait davantage, en Argolide, à une circulation des biens et des personnes dans une région densément occupée. Enfin, alors que certaines activités telles que le travail de l'ivoire se concentrent sur des sites palatiaux durant l'HR III B ${ }^{212}$, d'autres productions comme celle de la céramique dépassent largement le cadre palatial, comme l'illustrent les fours de potier découverts en contexte HR III C dans différentes régions de Grèce continentale. Les activités céramiques et métallurgiques ne cessent pas après l'effondrement des palais, comme l'atteste la présence de fours artisanaux, ni la production textile, comme le suggère la découverte d'outils en contexte HR III C sur différents sites. Les productions artisanales trouvent bien encore une place au sein des habitats mycéniens à la fin de l'âge du Bronze et laissent supposer un regain de vitalité, notamment à Tirynthe.

210. Poursat 1977, p. 139.

211. J. Chadwick, The Mycenaean World (1976), p. 141 (" the total of smiths in the kingdom was nearly $400 »$ ). Pour une estimation du nombre de potiers travaillant à temps partiel, voir T. Whitelaw (n. 45), p. 68 (« ca. 450-500 part-time potters within the polity as a whole»).

212. E.g. S. Voutsaki, « Economic Control, Power and Prestige in the Mycenaean World: the Archaeological Evidence ", dans S. Voutsaki, J. Killen (éds), Economy and Politics in the Mycenaean Palace States, Proceedings of a conference held on 1-3 July 1999 in the Faculty of classics (2001), p. 197. 


\section{ANNEXE 1}

\section{A. Liste de fours artisanaux de l'Helladique Récent}

(1) Aigeira, habitat, four de potier, HR III C, voir W. Alzinger et al. (n. 24), p. 402, fig. 10.

(2) Asinè, Maison H, four de potier, HR III, voir B. SJöBerg (n. 43), p. 90-91, fig. 1-2.

(3) Berbati, secteur sud-est, four de potier, HR II-HR II/III A1, voir ÅKeRström 1987, p. 24 25, fig. 5 .

(4) Dimini, terrain Tsakanika, four de potier, HR III A1-III A2, voir V. Adrimi-Sismani (n. 36, 1992), p. 223, fig. 1.

(5-6) Kirrha, terrain I. et M. Koureli, 2 fours de potier HM III-HR I, voir D. SKordA (n. 22), p. 651, fig. 1-2.

(7) Kirrha, terrain I. et M. Koureli, 1 four de potier, HR I-II, voir D. SKordA (n. 22), p. 651, fig. 1, 5-6.

(8-9) Kirrha, près du terrain précédent, 2 petits fours (probablement de potier), HR III, voir D. Skorda, J. Zurbach (n. 23), p. 546.

(10) Livanatès-Pyrgos (ant. Kynos), four de potier, HR III C Moyen, voir F. DAKoronia (n. 26), p. 218 , pl. $70 \gamma$.

(11) Pylos, Belvedere area, four de potier, HR I-II, voir C. W. Blegen et al. (n. 28), p. 19-20, fig. 44, 307-308.

(12) Thèbes, terrain A. Kordatzis, four métallurgique, HR III B1, voir Symeonoglou 1973, p. 12,15 .

(13) Thèbes, Maison de Kadmos, four de potier, HR, voir A. D. Keramopoullos (n. 50, 1911), p. 148-149.

(14) Tirynthe, Unterburg, four métallurgique, Raum 106, HR III C récent, voir K. KiLIaN (n. 5, 1978), p. 459-460, fig. 14.

(15) Tirynthe, Unterburg, four métallurgique, Raum 210, HR III B1, voir K. KILIAN (n. 5, 1988), p. 126, 135, fig. 31-32.

(16) Tirynthe, Unterburg, four de potier, Raum 119, HR III C ancien, voir K. Kilian (n. 6), p. 165-166, fig. 14, 18.

(17) Tirynthe, Mittelburg, four de potier, HR, voir H. DragendorfF (n. 8), p. 338-341, fig. 3.

(18) Velestino-Pherai (magoula Bakali), terrain M. G. Saranti, four de potier, HR III C, voir A. Batziou-Efstathiou (n. 27), p. 217, fig. 3.

(19) Volos, habitat, four métallurgique, HR, voir D. R. Theocharis (n. 58), p. 48-49. 
B. Liste de sites avec découverte de résidus métallurgiques

(1) Aidipsos-Koumbi, pièce A, coulée de métal, HR II/III A1, voir V. Nikolopoulos (n. 59), p. 353, fig. 7 .

(2) Thorikos-Vélatouri, habitat, HM III-HR I, voir J. SERVAIs (n. 60), p. 22-23, fig. 16.

C. Liste de sites avec découverte d'ivoire (pièces semi-finies ou fragments)

(1) Mycènes, Maison des Boucliers, Maison des Sphinx, HR III B1, voir Tournavitou 1995, p. 20-27, 45-53, 123-206, pl. 15-28 ; Maison des Artisans, voir G.E. Mylonas (n. 72), p. 425 ; Tournavitou 1997, p. 237.

(2) Pylos, Palais, bâtiment principal, HR III B2, voir PN I, p. 132-144, 151-163, fig. 280286 ; Bâtiment Nord-Est, voir PN I, p. 325.

(3) Thèbes, la Cadmée, terrain A. Kordatzis, HR III B(1 ?), voir Symeonoglou 1973, p. 12, 16, fig. 7-8, 218-262; terrain des frères Tzortzis, HR III B1, voir K. Demakopoulou (n. 81), p. 168, pl. $54 \delta$; terrain M. Loukos, HR III B1, voir SAMPSON 1985, p. 28, fig. 4-6, 10 . 